\title{
Single-cell profiling of fatty acid uptake using surface- immobilized dendrimers
}

Zhili Guo, ${ }^{\dagger}, \#$ Hanjun Cheng, ${ }^{\ddagger}$ Zhonghan Li, ${ }^{\dagger}$ Shiqun Shao, ${ }^{\dagger, \ddagger}$ Priyanka Sarkar, ${ }^{\dagger}$ Siwen Wang, ${ }^{\dagger}{ }^{\text {Rohit Chaudhuri, }}{ }^{\dagger}$ Nicole G. Perkins, ${ }^{\dagger}$ Fei Ji, ${ }^{\dagger}$ Wei Wei ${ }^{\ddagger},{ }^{*}$ and Min Xue ${ }^{\dagger,},{ }^{\star}$

†Department of Chemistry, University of California, Riverside, Riverside, California 92521, United States łInstitute for Systems Biology, Seattle, Washington 98109, United States

\# These authors contributed equally

\section{Supporting Information}




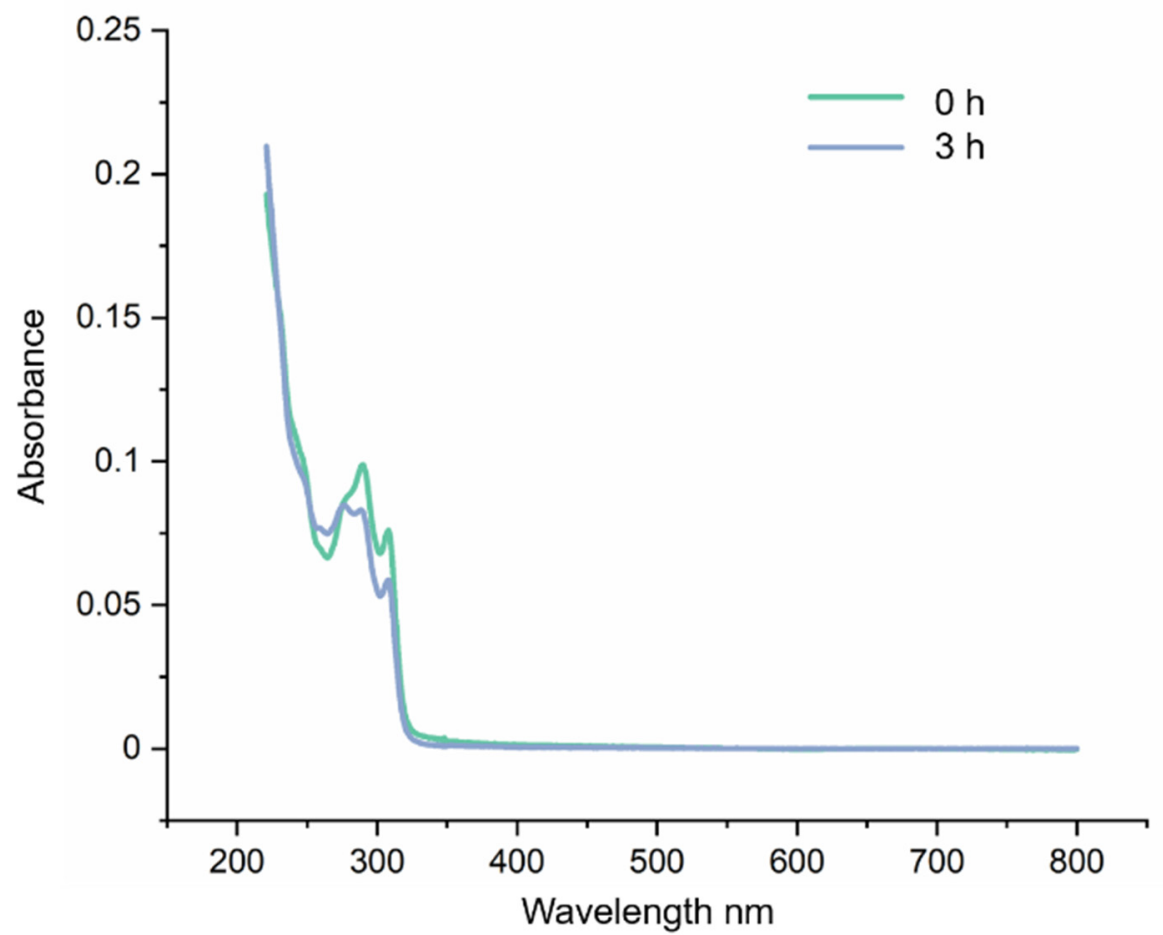

Figure S1. UV-Vis spectrum of $10 \mu \mathrm{M}$ DBCO reacting with $50 \mu \mathrm{M} F A-\mathrm{N}_{3}$. After 3 hours, no significant absorbance decrease at $310 \mathrm{~nm}$ was observed. 


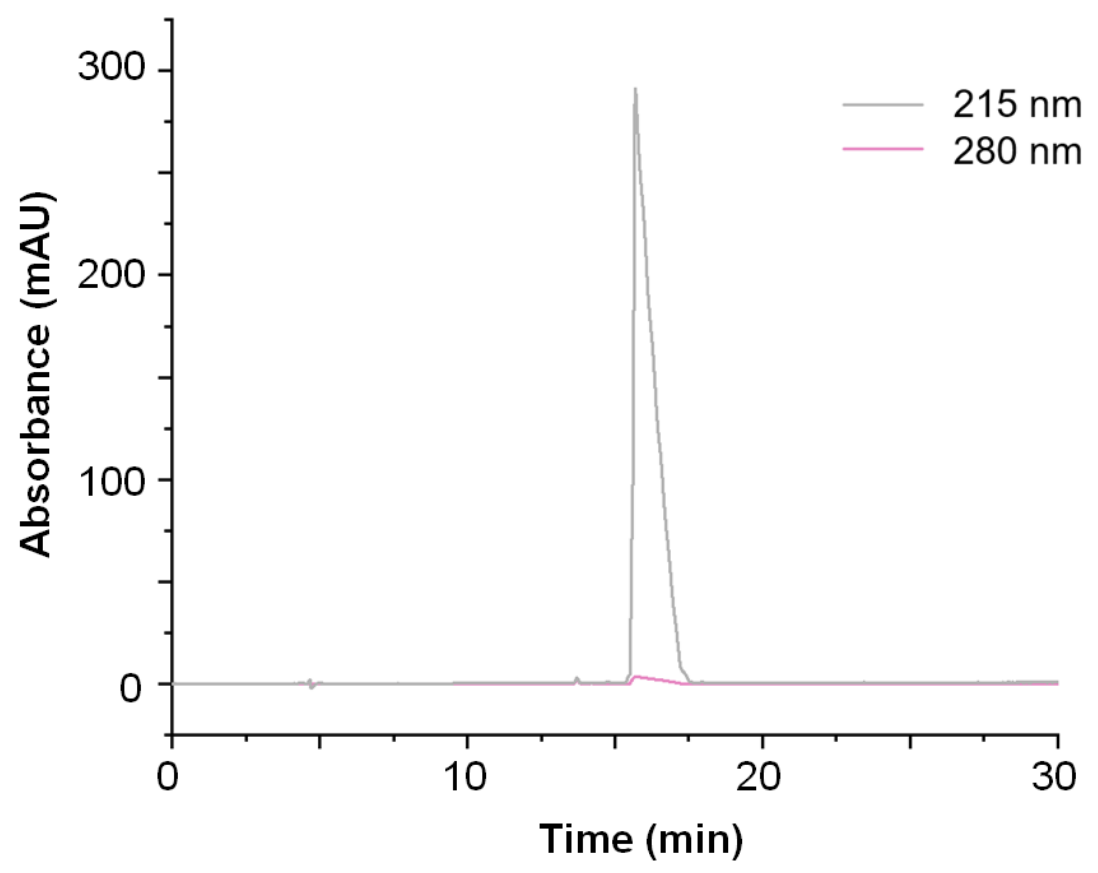

Figure S2. HPLC chromatogram of the synthesized G-3 polylysine dendrimer scaffold. The HPLC was performed on a Thermo Ultimate 3000BX instrument, using a C18 reversed-phase column (Phenomenex, Kinetex $5 \mu \mathrm{m}$ EVO, $250 \times 21.2 \mathrm{~mm}$ ). The solvents used were $\mathrm{A}$ : $\mathrm{H}_{2} \mathrm{O}$ with $0.1 \%$ TFA, B: acetonitrile with $0.1 \%$ TFA. The method used was $0-75 \%$ B in 30 min, linear gradient. 


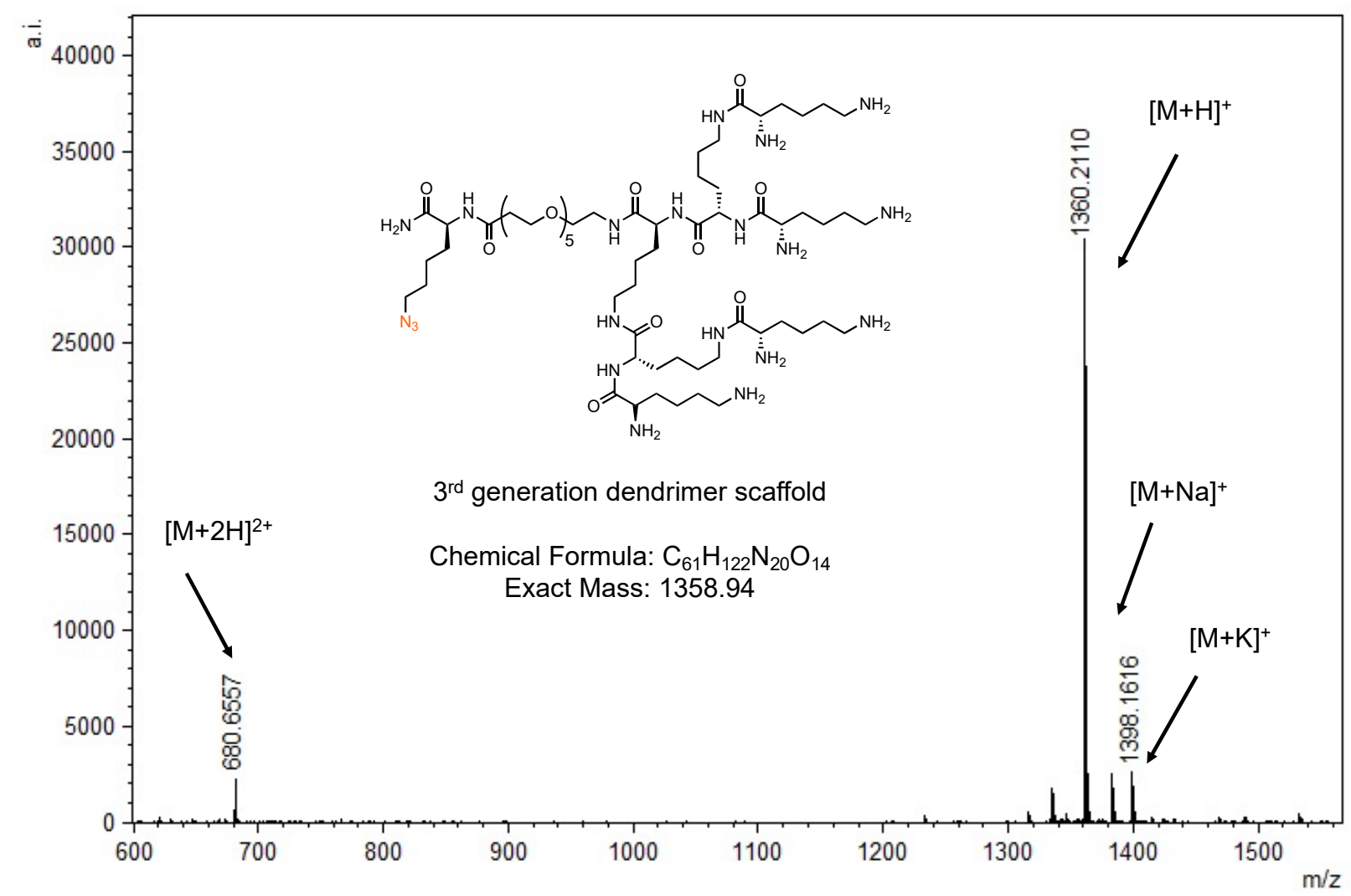

Figure S3. Mass spectrum of the $3^{\text {rd }}$ generation (G-3) polylysine dendrimer scaffold (MALDI-TOF, AB Sciex 5800). $[\mathrm{M}+\mathrm{H}]^{+}$calculated: 1359.94 , found 1360.21 . 


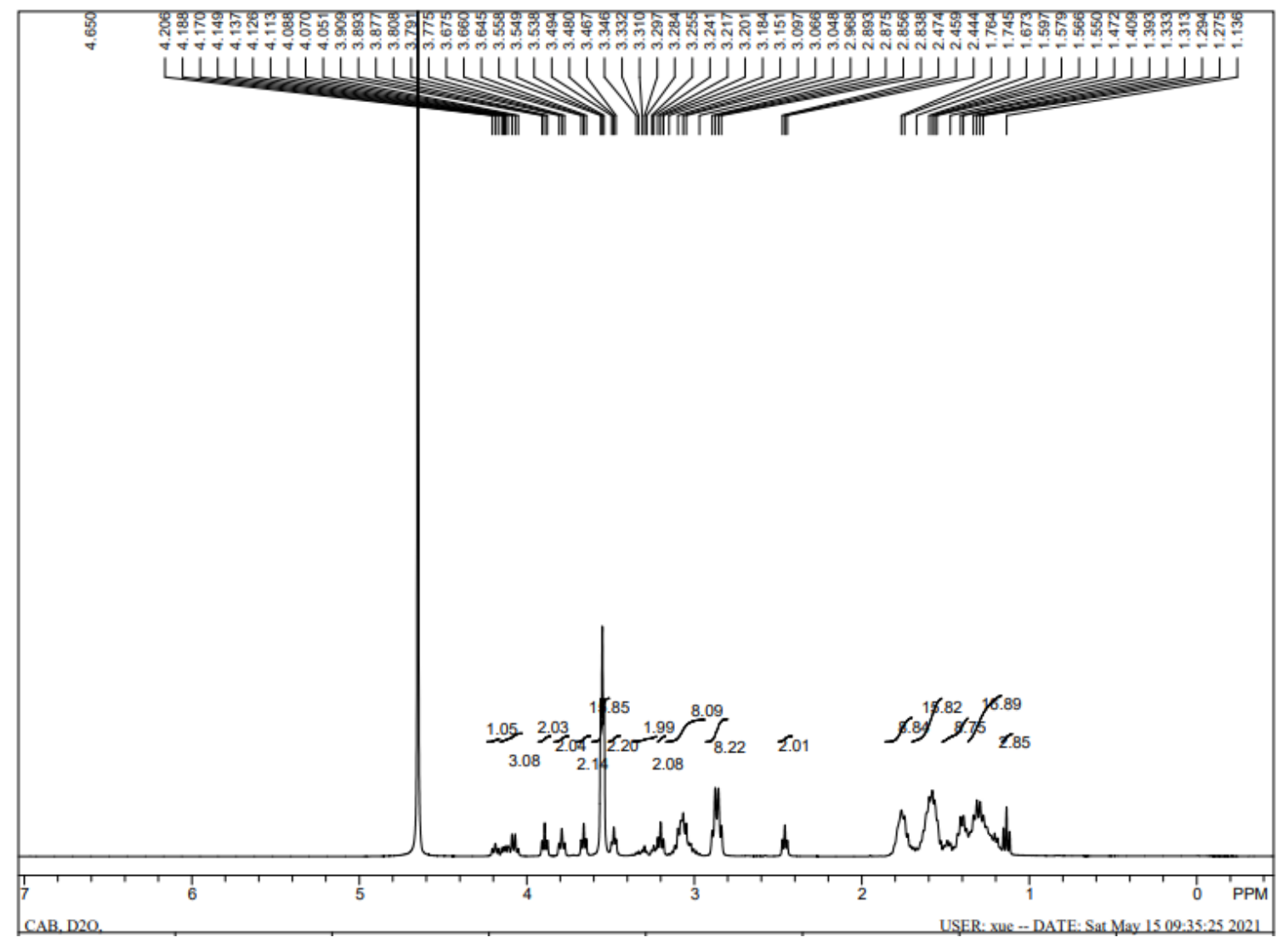

Figure S4-1. ${ }^{1} \mathrm{H}-\mathrm{NMR}$ spectrum of the G-3 polylysine dendrimer scaffold. 

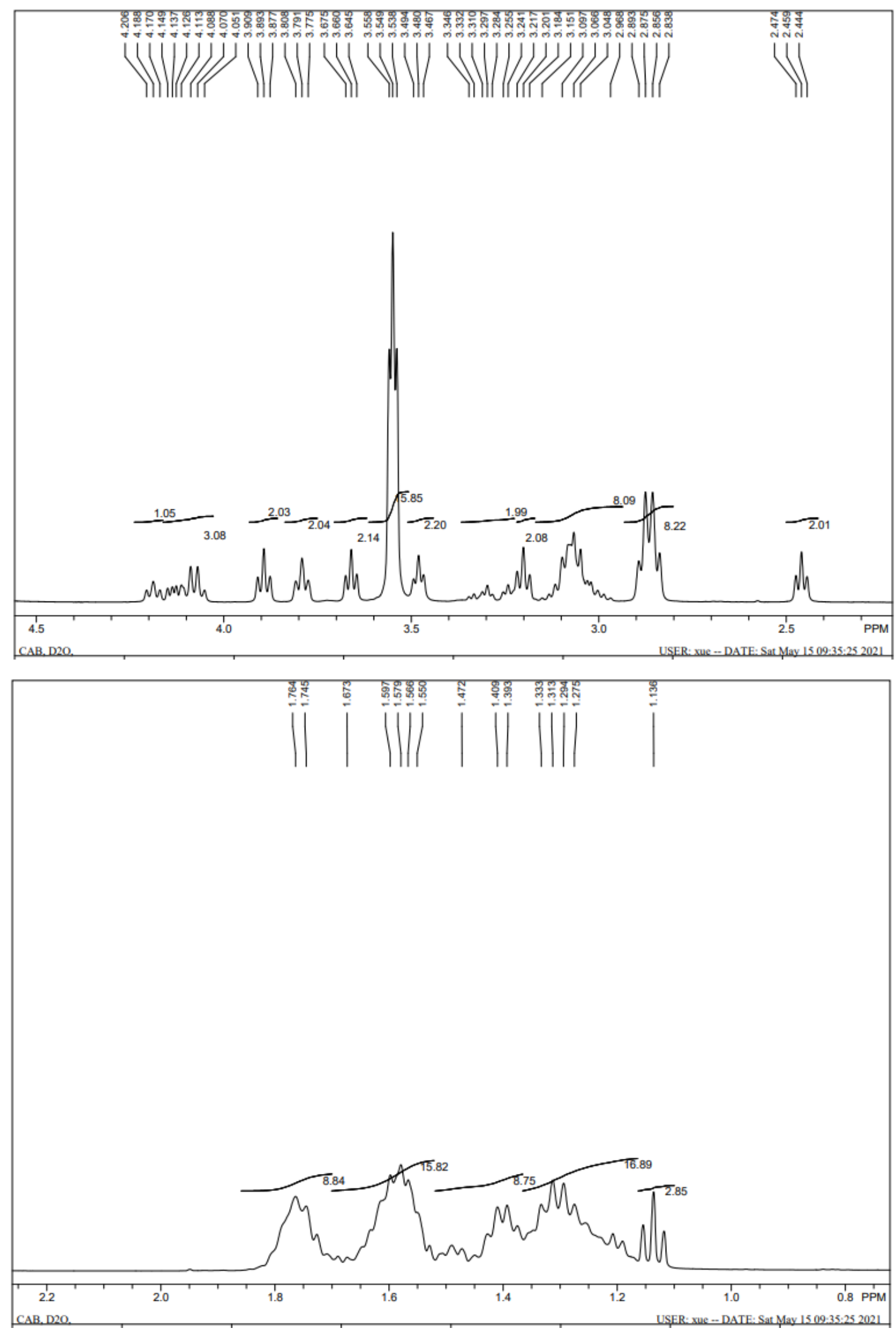

Figure S4-2. ${ }^{1} \mathrm{H}-\mathrm{NMR}$ spectra (zoom-in) of the G-3 polylysine dendrimer scaffold. 


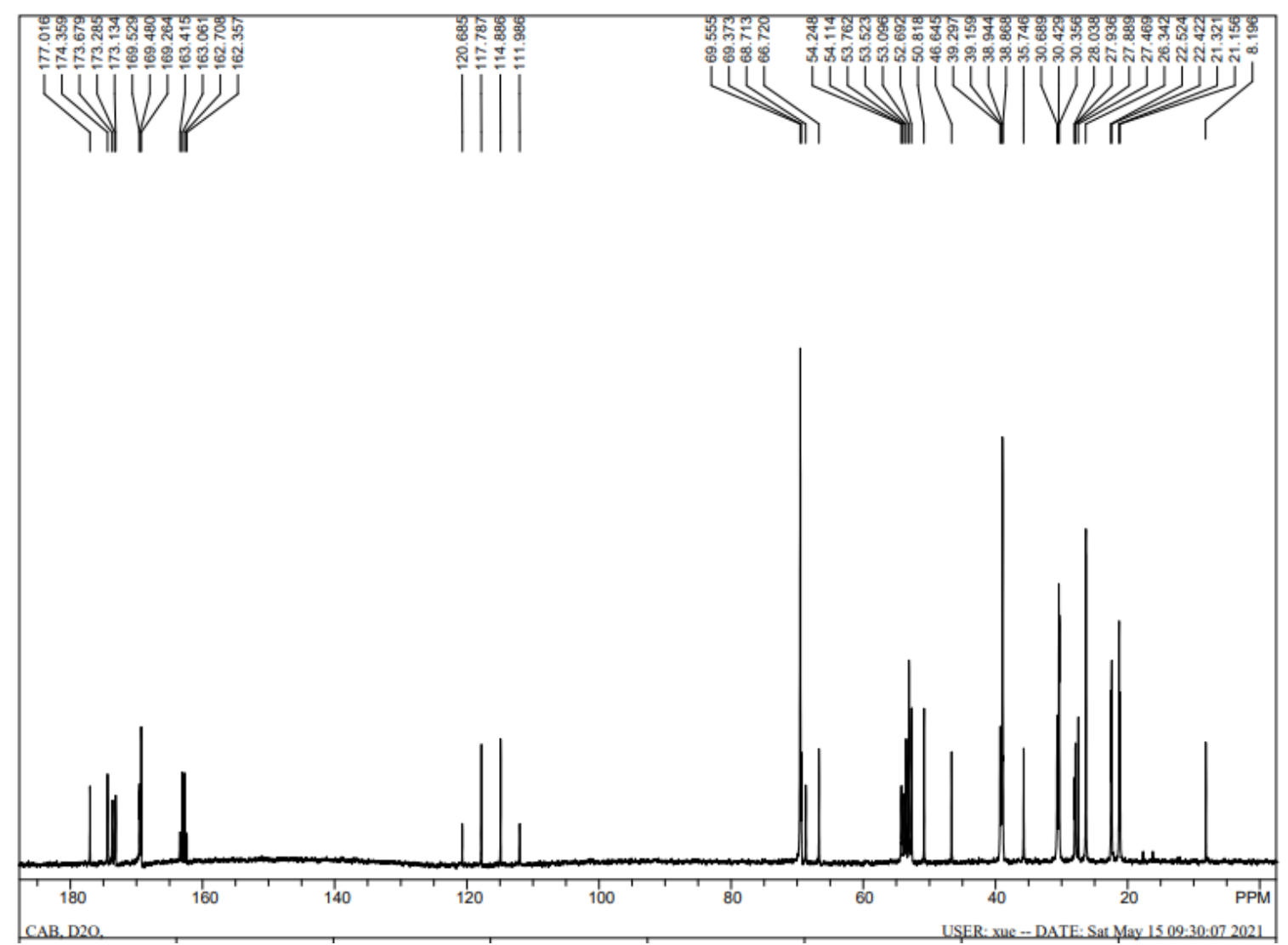

Figure S5-1. ${ }^{13} \mathrm{C}-\mathrm{NMR}$ spectrum of the G-3 dendrimer scaffold.

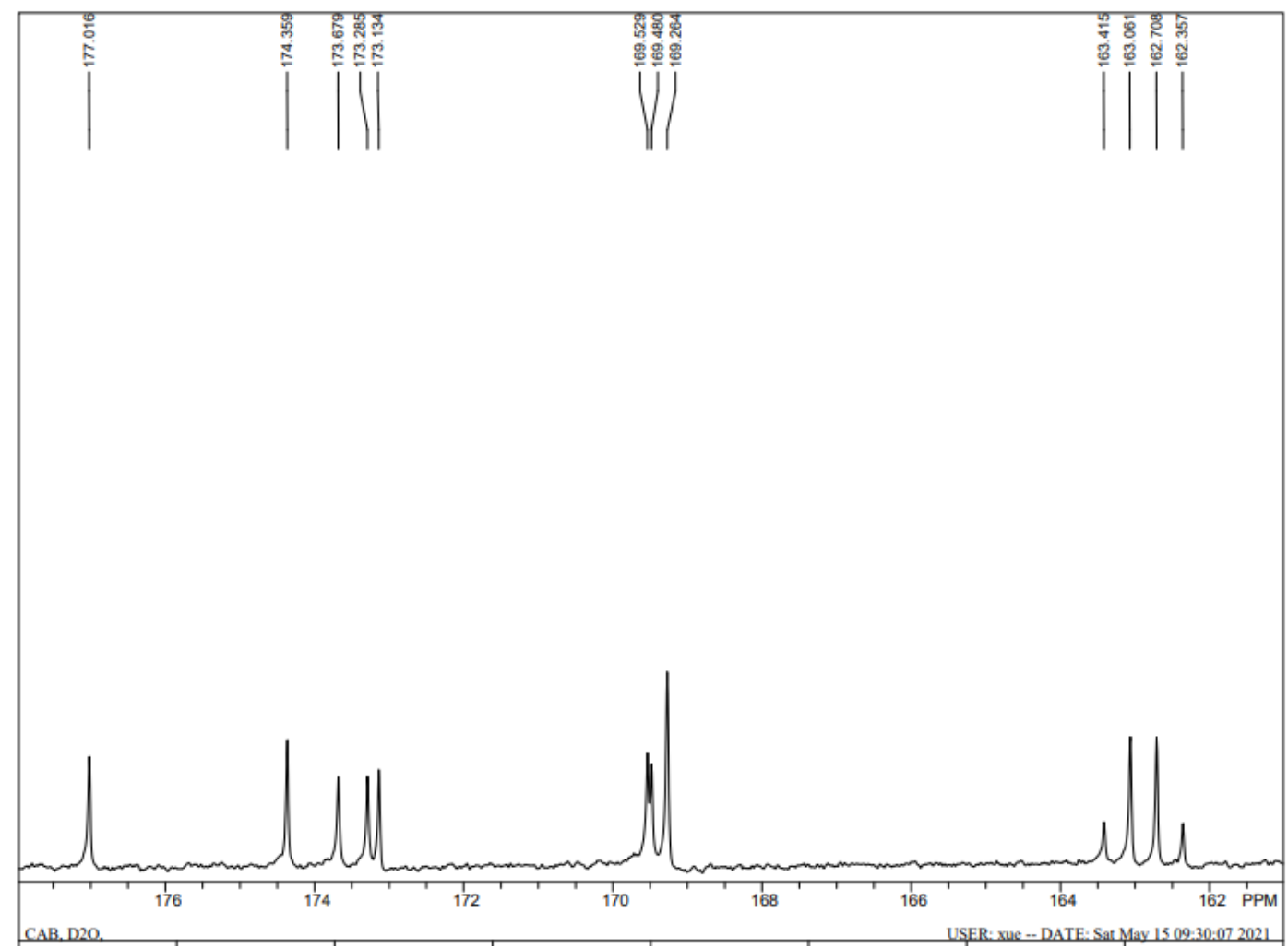

Figure S5-2. ${ }^{13} \mathrm{C}-\mathrm{NMR}$ spectrum (zoom-in) of the G-3 polylysine dendrimer scaffold. 


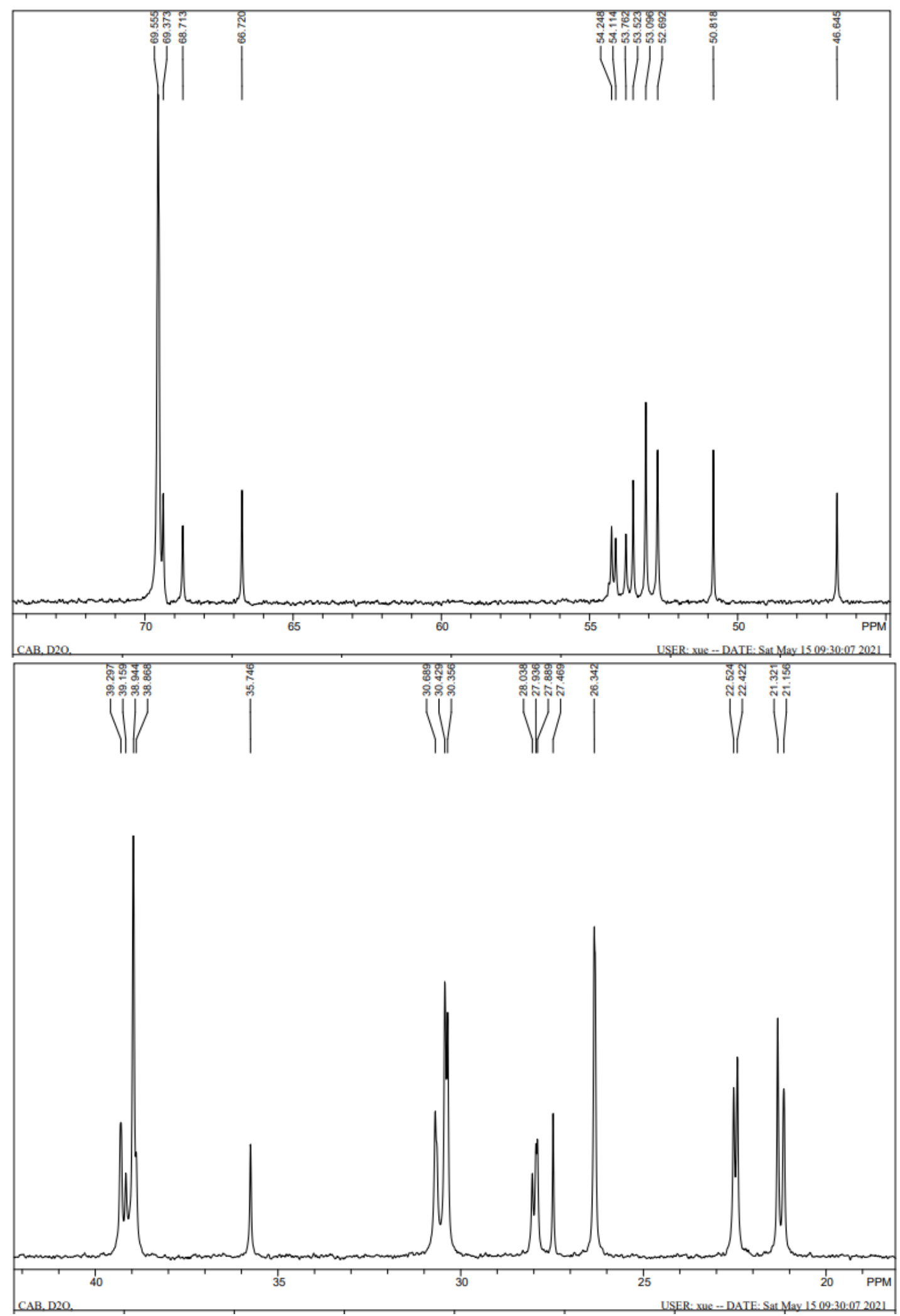

Figure S5-3. ${ }^{13} \mathrm{C}-\mathrm{NMR}$ spectra (zoom-in) of the G-3 polylysine dendrimer scaffold. 


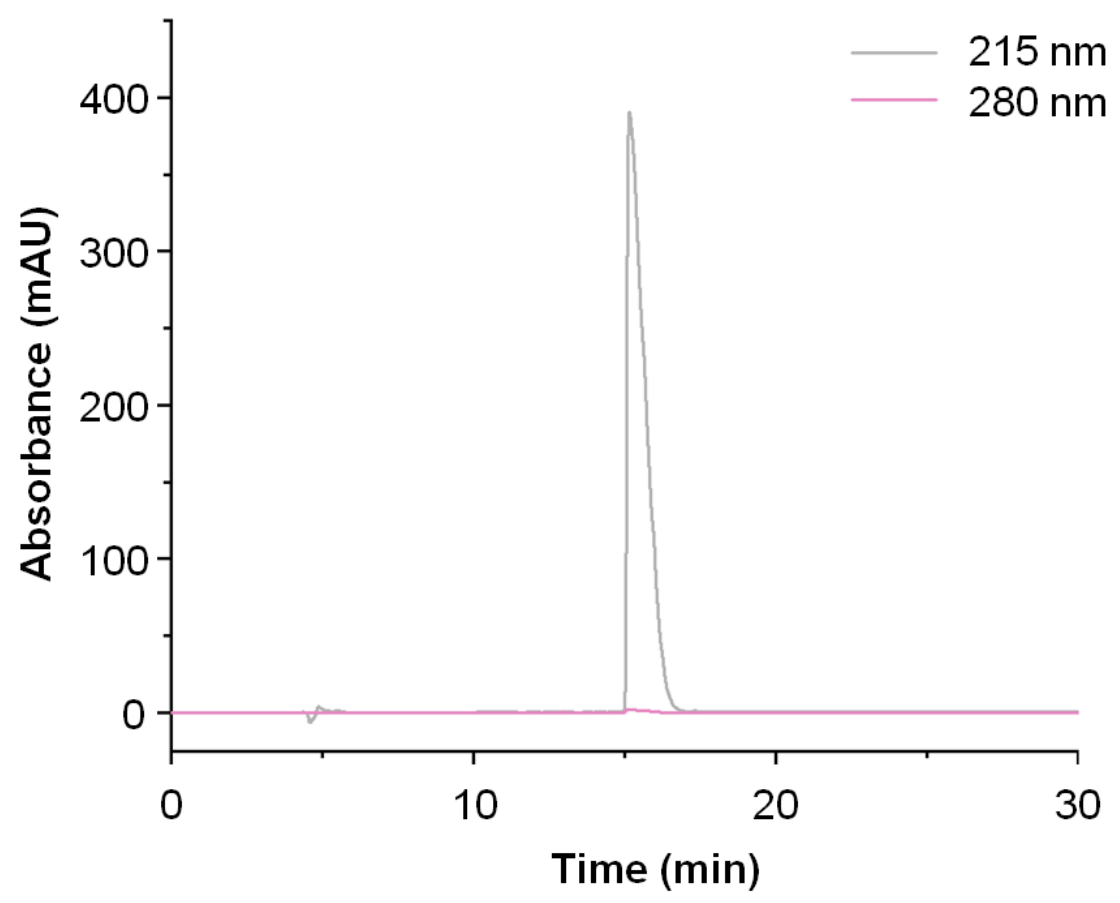

Figure S6. HPLC chromatogram of the synthesized G-4 polylysine dendrimer scaffold. The HPLC was performed on a Thermo Ultimate 3000BX instrument, using a C18 reversed-phase column (Phenomenex, Kinetex $5 \mu \mathrm{m}$ EVO, $250 \times 21.2 \mathrm{~mm}$ ). The solvents used were A: $\mathrm{H}_{2} \mathrm{O}$ with $0.1 \%$ TFA, B: acetonitrile with $0.1 \%$ TFA. The method used was $0-75 \% \mathrm{~B}$ in $30 \mathrm{~min}$, linear gradient. 


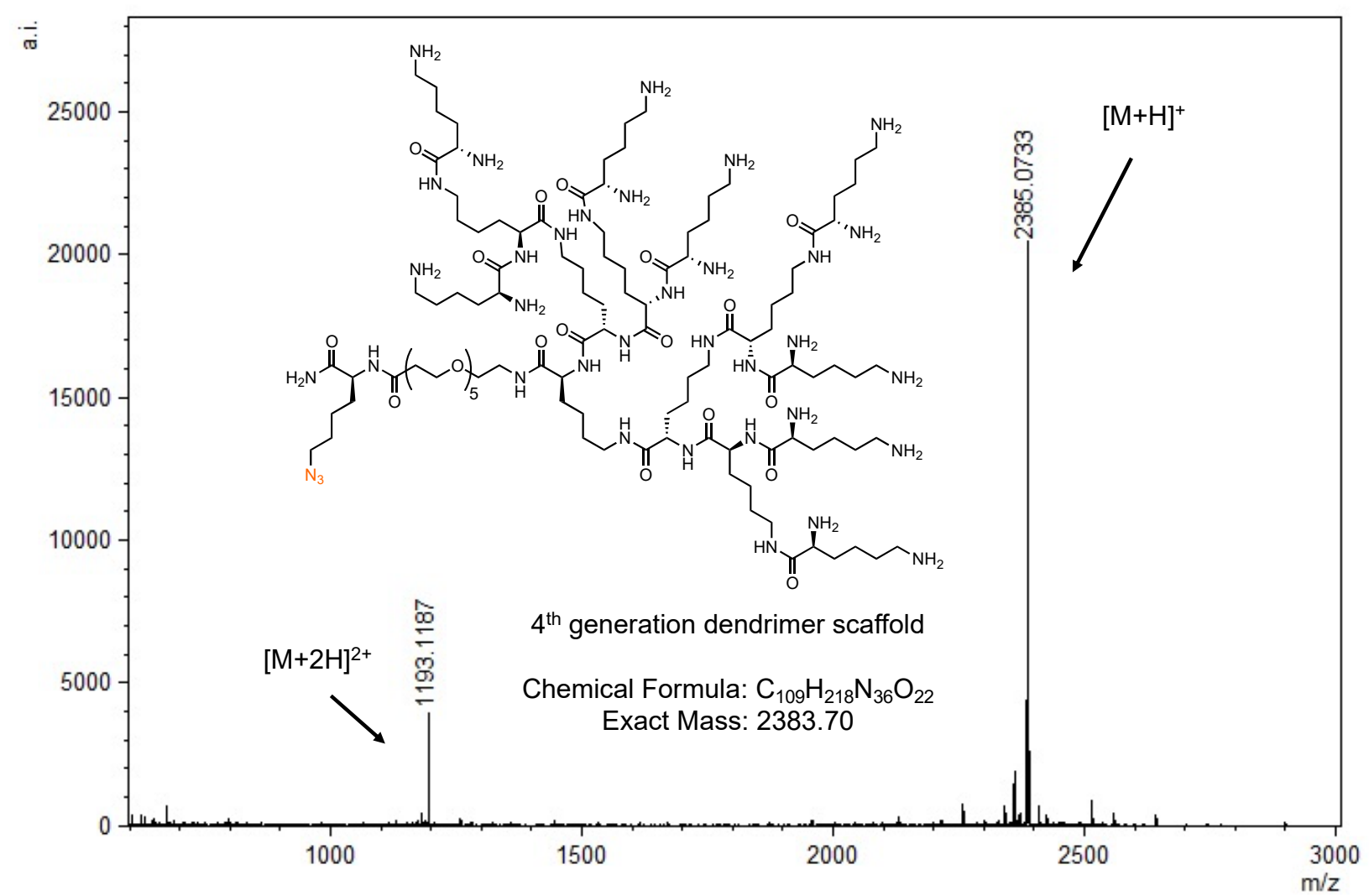

Figure S7. Mass spectrum for the $4^{\text {th }}$ generation (G-4) polylysine dendrimer scaffold (MALDI-TOF, AB Sciex 5800). $[\mathrm{M}+\mathrm{H}]^{+}$calculated: 2384.70 , found 2385.07 . 


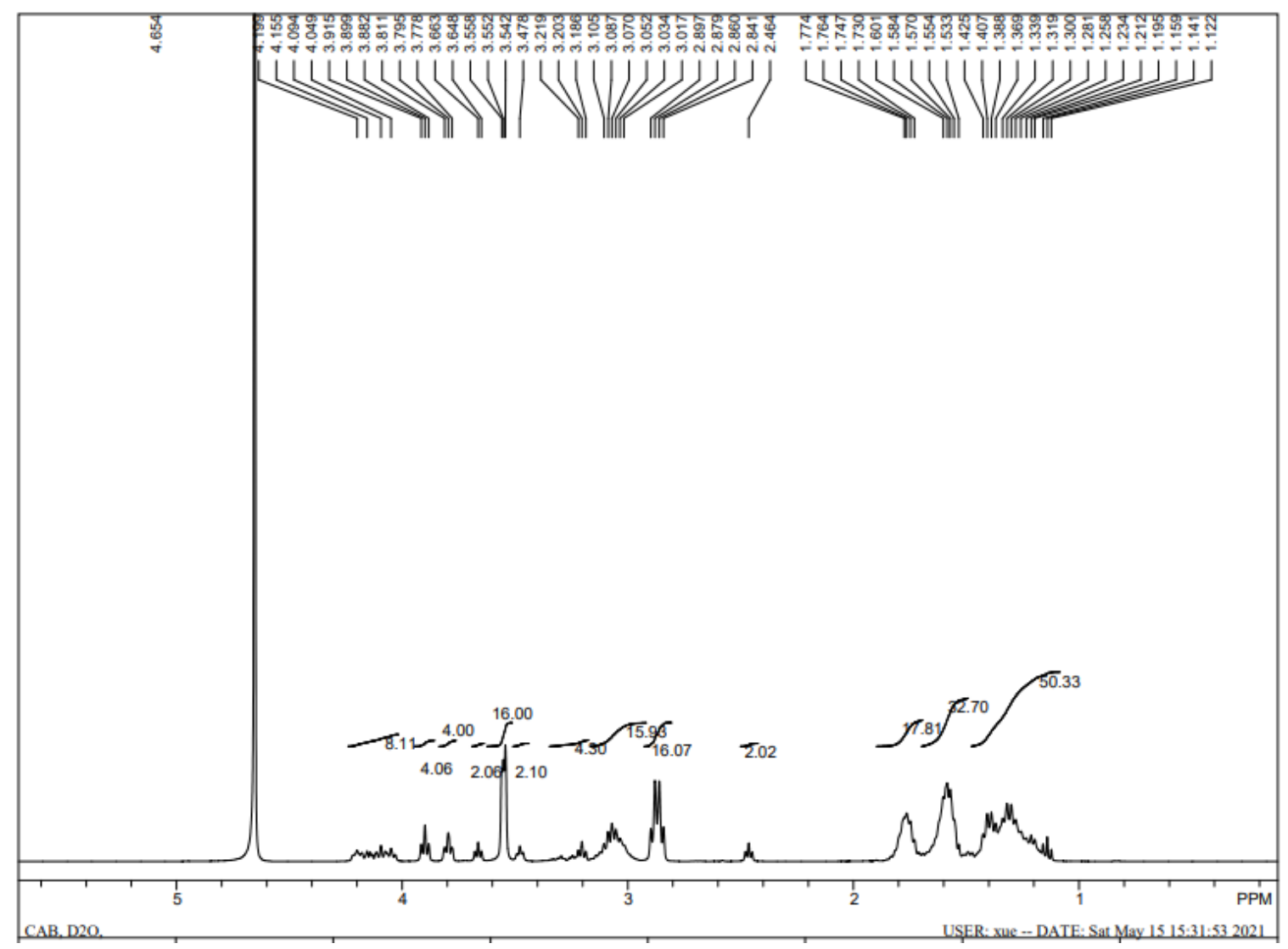

Figure S8-1. ${ }^{1} \mathrm{H}-\mathrm{NMR}$ spectrum of the G-4 polylysine dendrimer scaffold. 


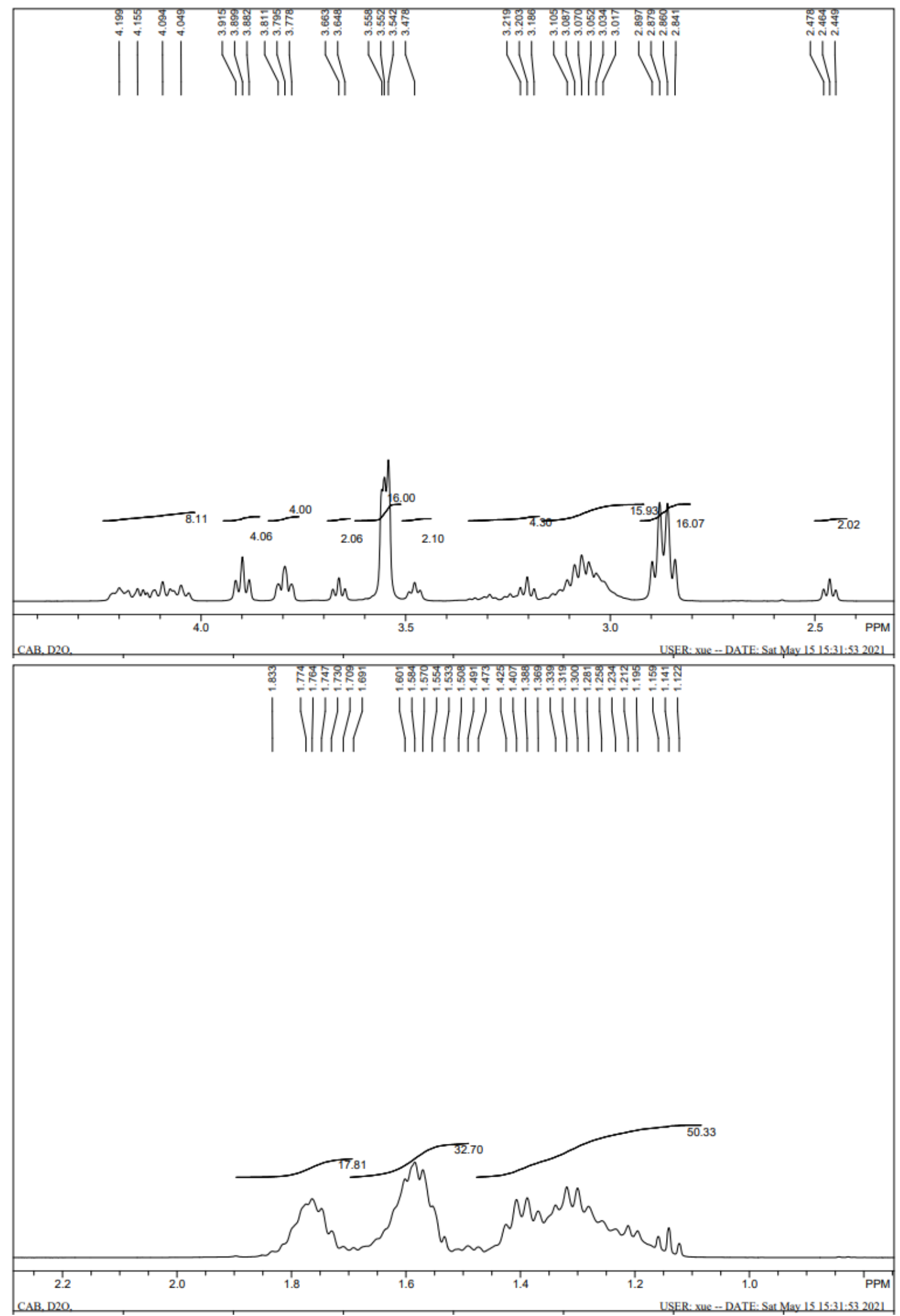

Figure S8-2. ${ }^{1} \mathrm{H}-\mathrm{NMR}$ spectra (zoom-in) of the G-4 polylysine dendrimer scaffold. 


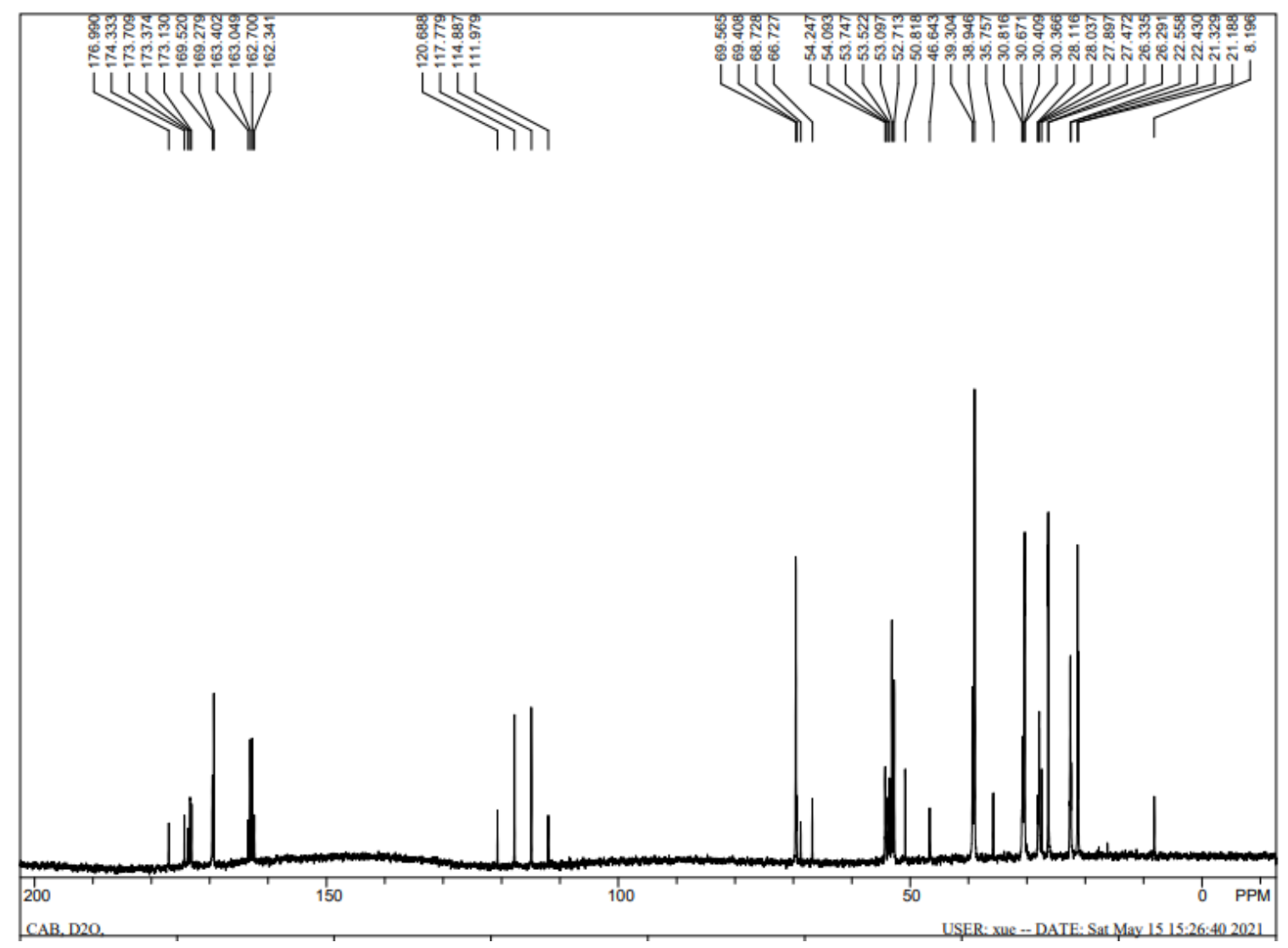

Figure S9-1. ${ }^{13} \mathrm{C}-\mathrm{NMR}$ spectrum of the G-4 polylysine dendrimer scaffold.

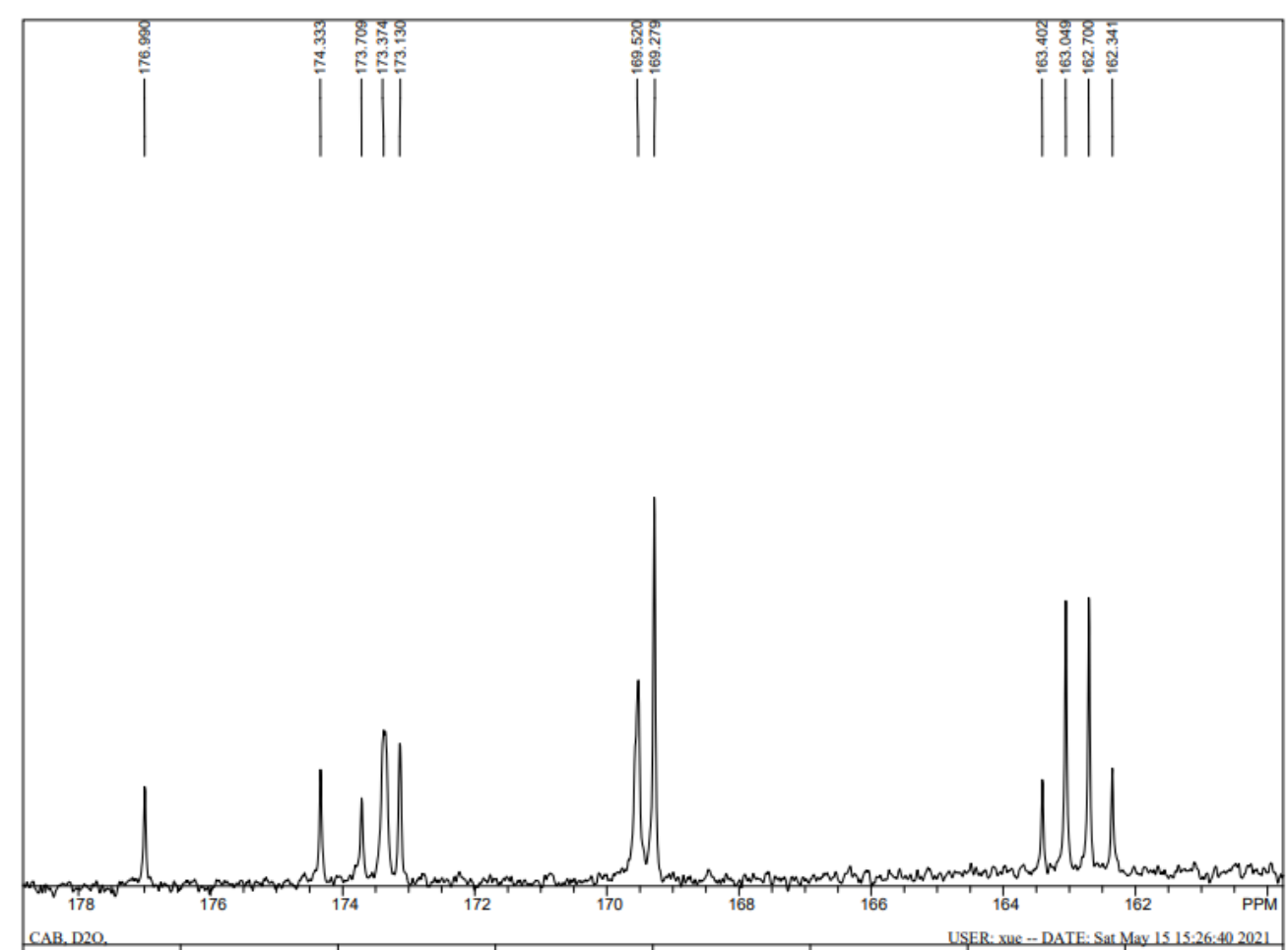

Figure S9-2. ${ }^{13}$ C-NMR spectrum (zoom-in) of the G-4 polylysine dendrimer scaffold. 


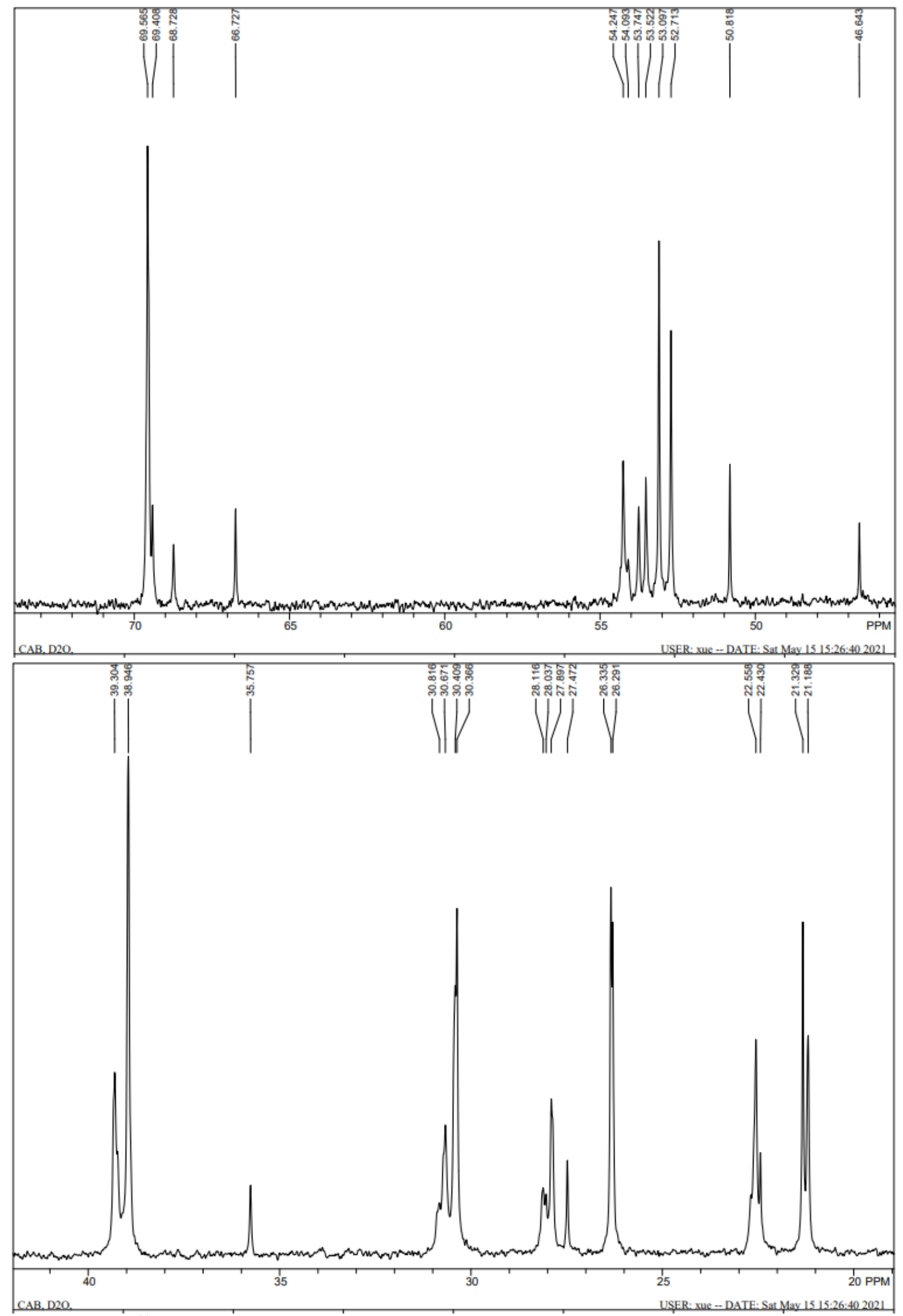

Figure S9-3. ${ }^{13} \mathrm{C}-N M R$ spectra (zoom-in) of the G-4 polylysine dendrimer scaffold. 

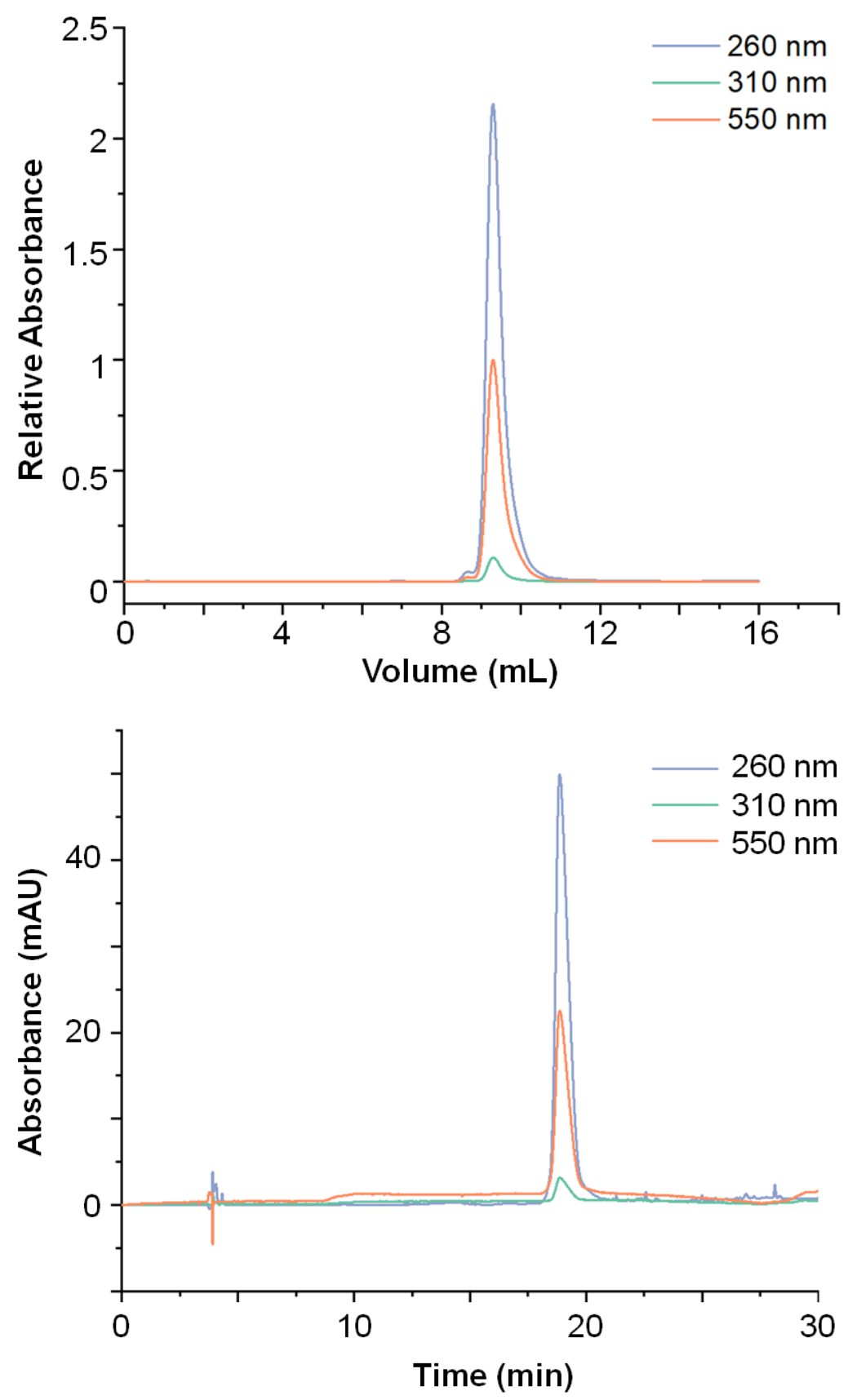

Figure S10. The FPLC (top) and HPLC (bottom) chromatograms of the synthesized ssDNA-Cy3-DBCO. The FPLC was performed on a Cytiva AKTA Pure instrument with a size-exclusion chromatography column (Cytiva, Superdex 30 increase 10/300 GL). An $\mathrm{NH}_{4} \mathrm{HCO}_{3}$ solution ( $50 \mathrm{mM}$ in water, $\mathrm{pH}$ 7.8) was used as the eluent. The peak absorbance at $310 \mathrm{~nm}$ was 0.11 , which corresponded to 1 DBCO group per DNA. The HPLC was performed on a Thermo Ultimate 3000 instrument, using a C18 reversed-phase column (Phenomenex, Kinetex $2.6 \mu \mathrm{m}$ EVO, 250 x $4.6 \mathrm{~mm}$ ). The solvents used were A: $400 \mathrm{mM} \mathrm{HFIP}(1,1,1,3,3,3-$ Hexafluoro-2-propanol) / $2.3 \mathrm{mM}$ triethylamine in water, $\mathrm{pH} 7.0$, B: methanol. The method used was $0-100 \%$ $B$ in 30 min, linear gradient. 


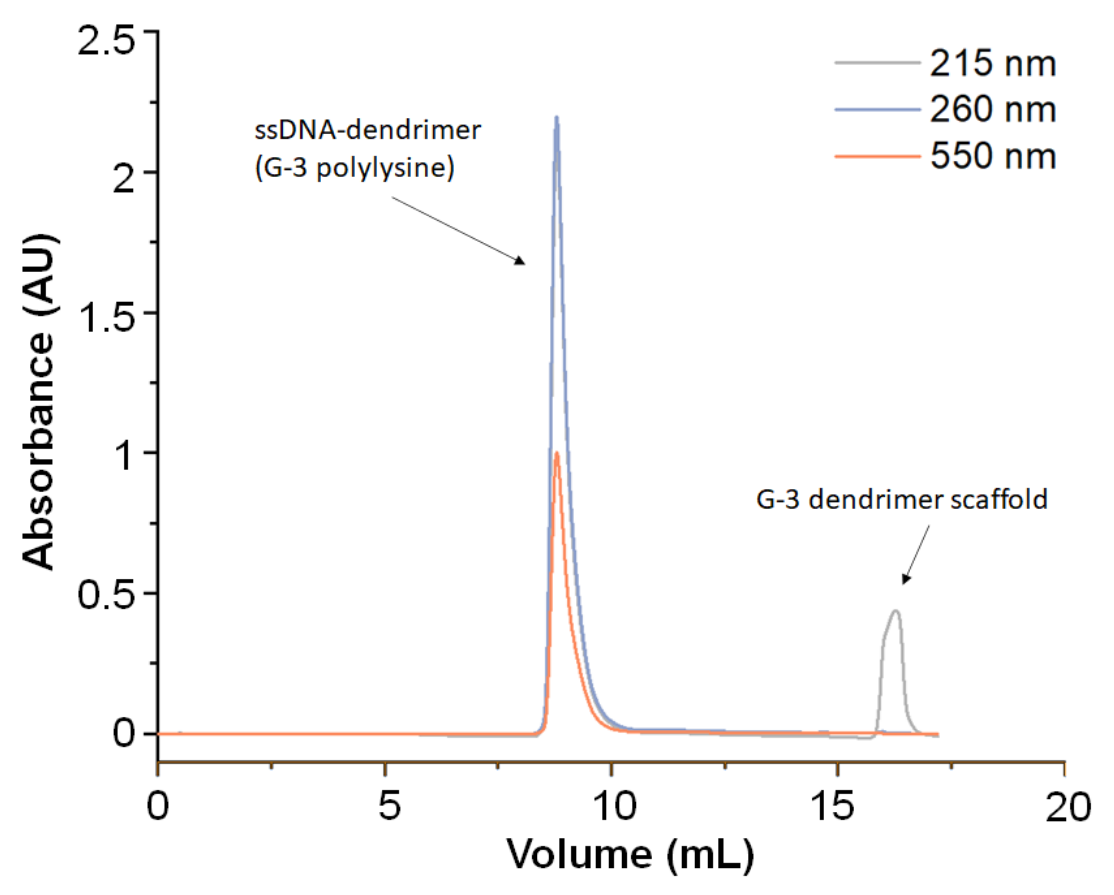

Figure S11. The FPLC chromatogram of the synthesized ssDNA-dendrimer (G-3 polylysine) scaffold. The FPLC was performed on a Cytiva AKTA Pure instrument with a size-exclusion chromatography column (Cytiva, Superdex 30 increase 10/300 GL). 3X PBS solution ( $\mathrm{pH} 7.5$ ) was used as the eluent. Note that this high salt condition was critical to solubilizing the product. Lower salt concentrations led to rapid precipitation. 


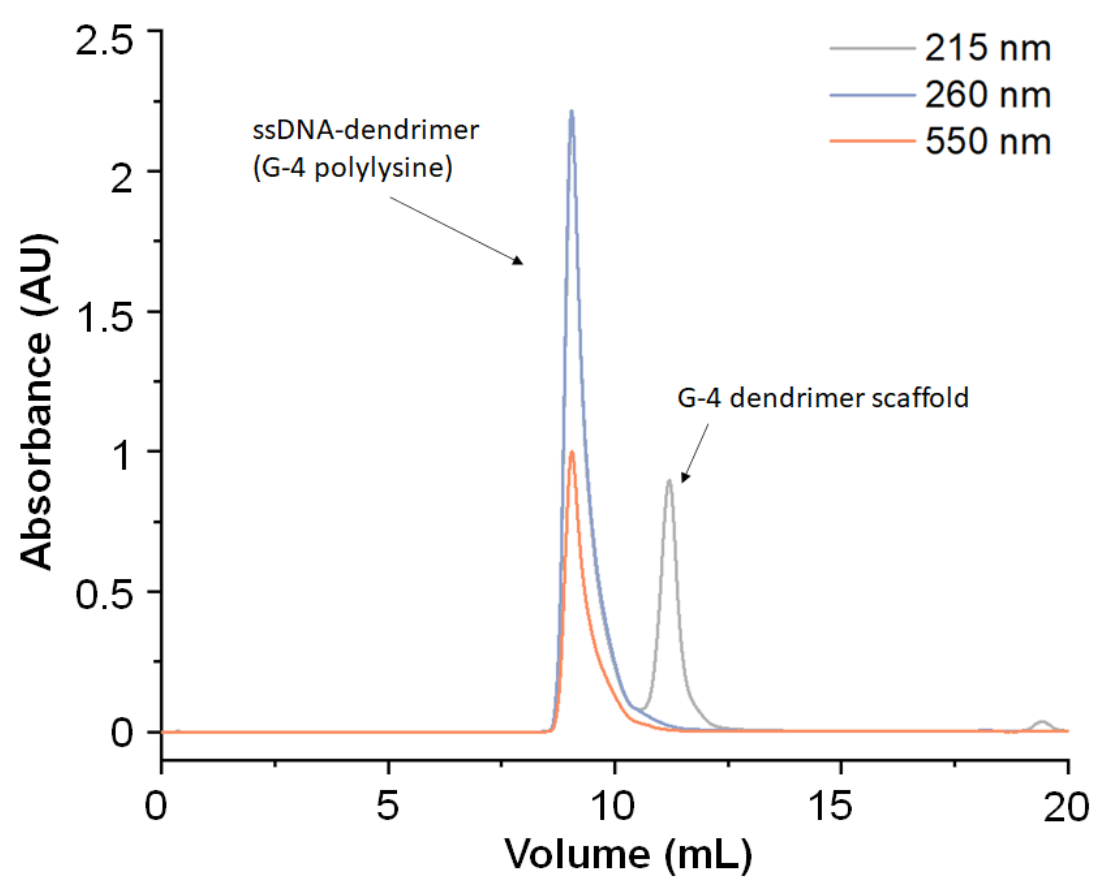

Figure S12. The FPLC chromatogram of the synthesized ssDNA-dendrimer (G-4 polylysine) scaffold. The FPLC was performed on a Cytiva AKTA Pure instrument with a size-exclusion chromatography column (Cytiva, Superdex 30 increase 10/300 GL). 3X PBS solution (pH 7.5) was used as the eluent. Note that this high salt condition was critical to solubilizing the product. Lower salt concentrations led to rapid precipitation. 


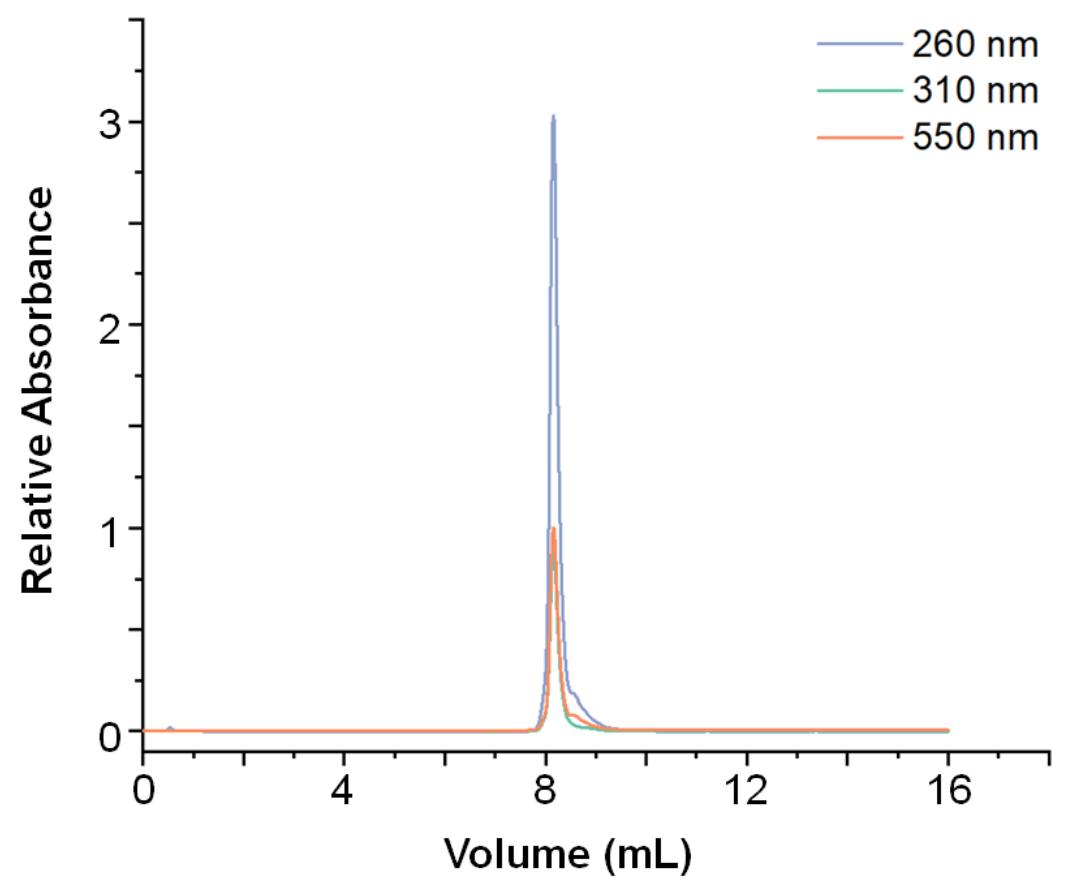

Figure S13. The FPLC chromatogram of the final ssDNA-dendrimer (G-3 DBCO) product. The FPLC was performed on a Cytiva AKTA Pure instrument with a size-exclusion chromatography column (Cytiva, Superdex 30 increase 10/300 GL). An $\mathrm{NH}_{4} \mathrm{HCO}_{3}$ solution (50 mM in water, $\mathrm{pH} 7.8$ ) was used as the eluent. The peak absorbance at $310 \mathrm{~nm}$ was 0.89 , which corresponded to 8 DBCO groups per DNA. 


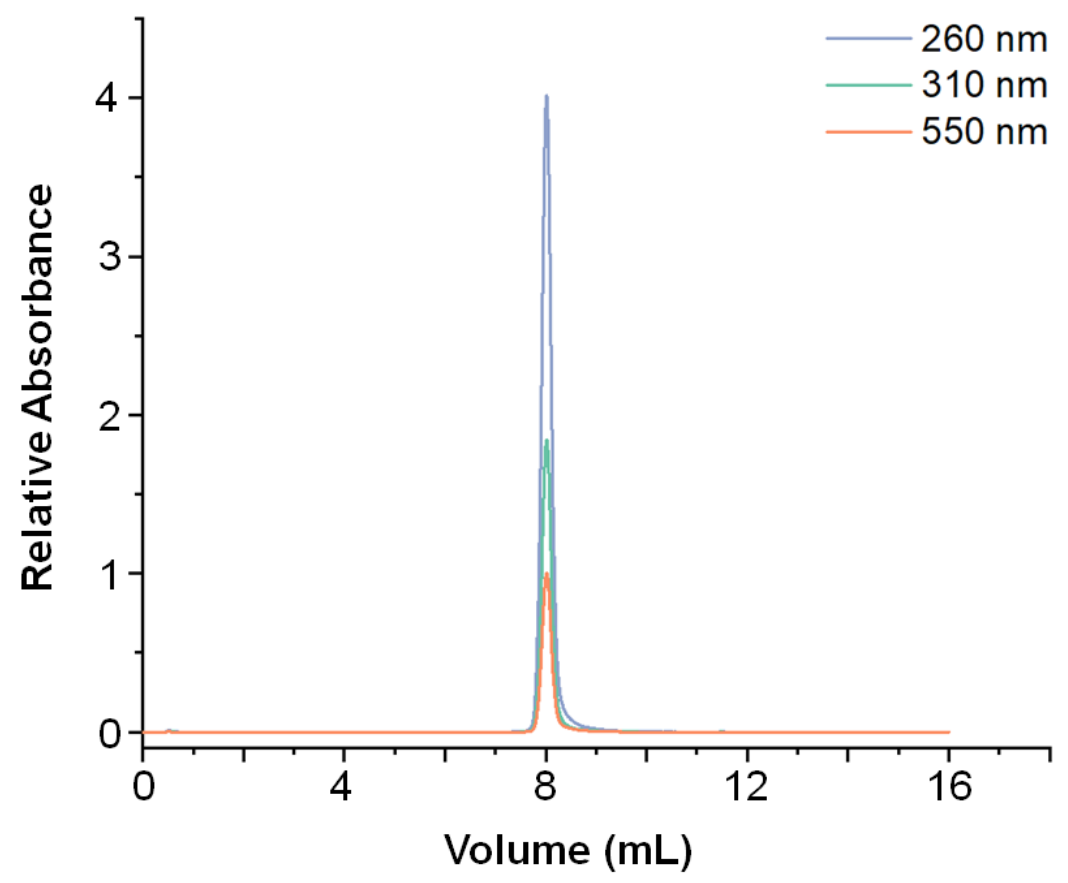

Figure S14. The FPLC chromatogram of the final ssDNA-dendrimer (G-4 DBCO) product. The FPLC was performed on a Cytiva AKTA Pure instrument with a size-exclusion chromatography column (Cytiva, Superdex 30 increase 10/300 GL). An $\mathrm{NH}_{4} \mathrm{HCO}_{3}$ solution (50 mM in water, $\mathrm{pH} 7.8$ ) was used as the eluent. The peak absorbance at $310 \mathrm{~nm}$ was 1.84 , which corresponded to 16 DBCO groups per DNA. 

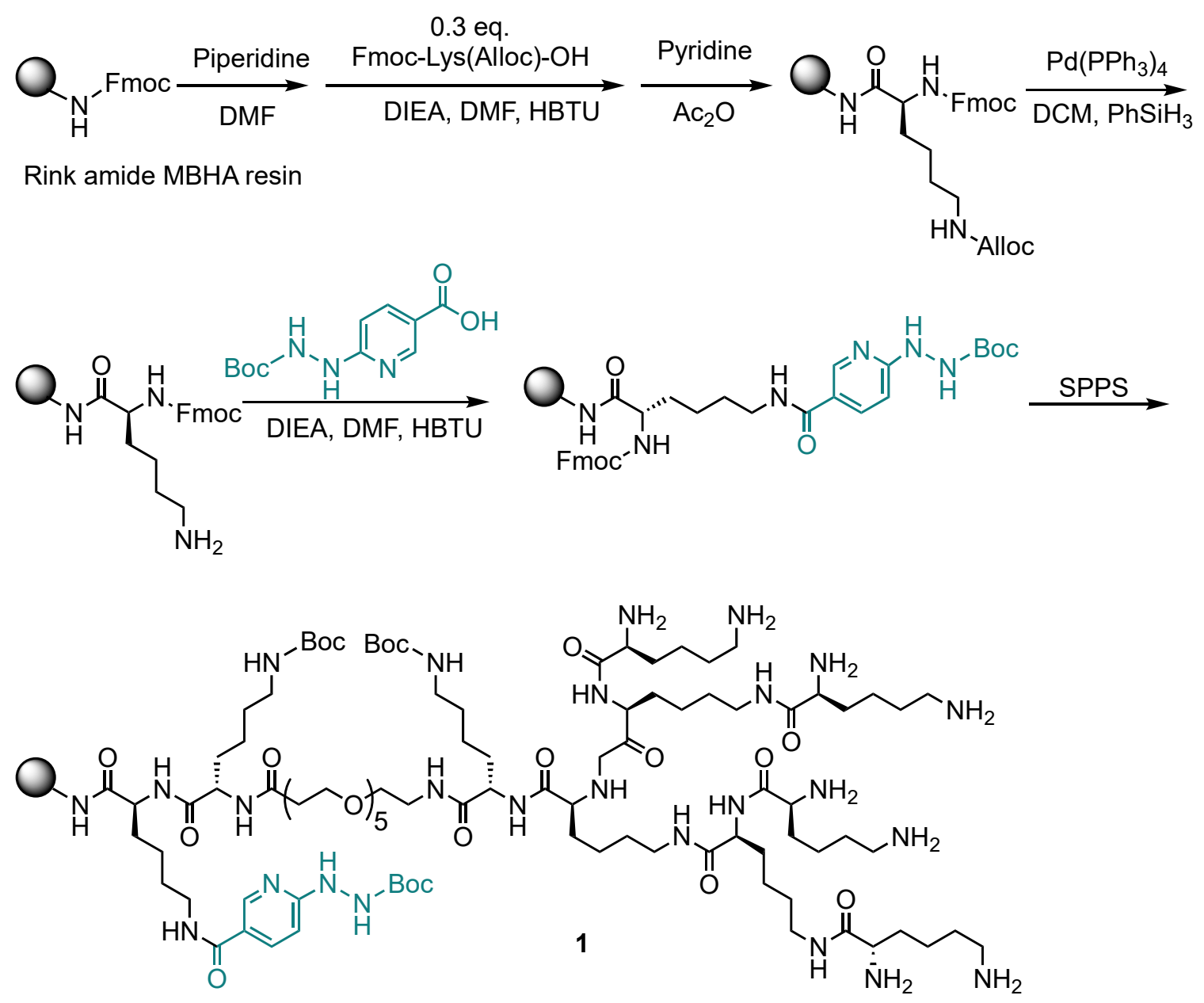

Figure S15. The first attempt to conjugate the dendrimer to ssDNA through a hydrazone linkage. G-3 and G-4 scaffolds were synthesized on Rink amide and later conjugated to Boc-HNA, which would link to ssDNA. The loading capacity of rink amide MBHA was reduced to $0.2 \mathrm{mmol} / \mathrm{g}$ at the beginning of the synthesis to allow more room for the DBCO-dendrimer.

Method A:
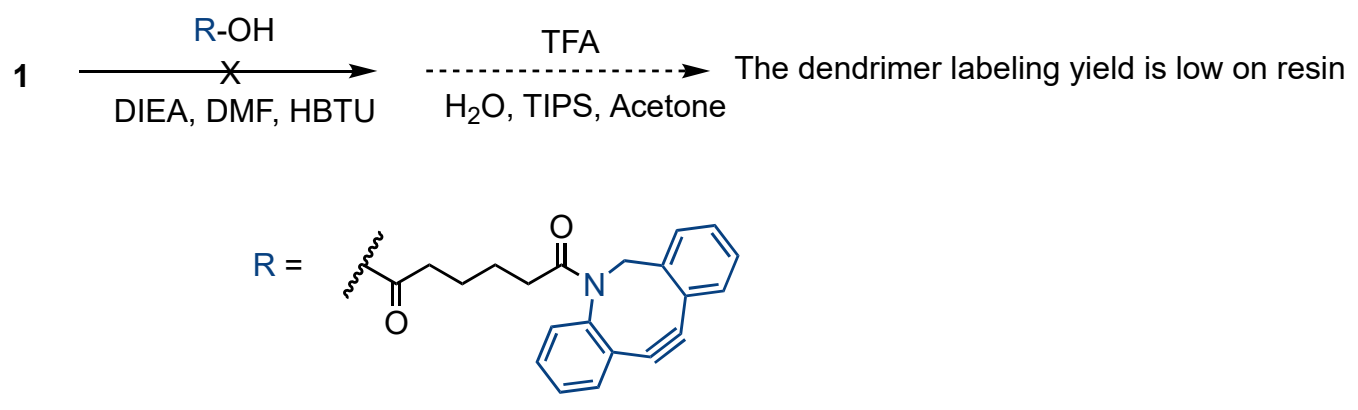

Figure S16. The attempt of labeling dendrimer with $\mathrm{DBCO}$ on resin led to a very low yield. 
Method B:

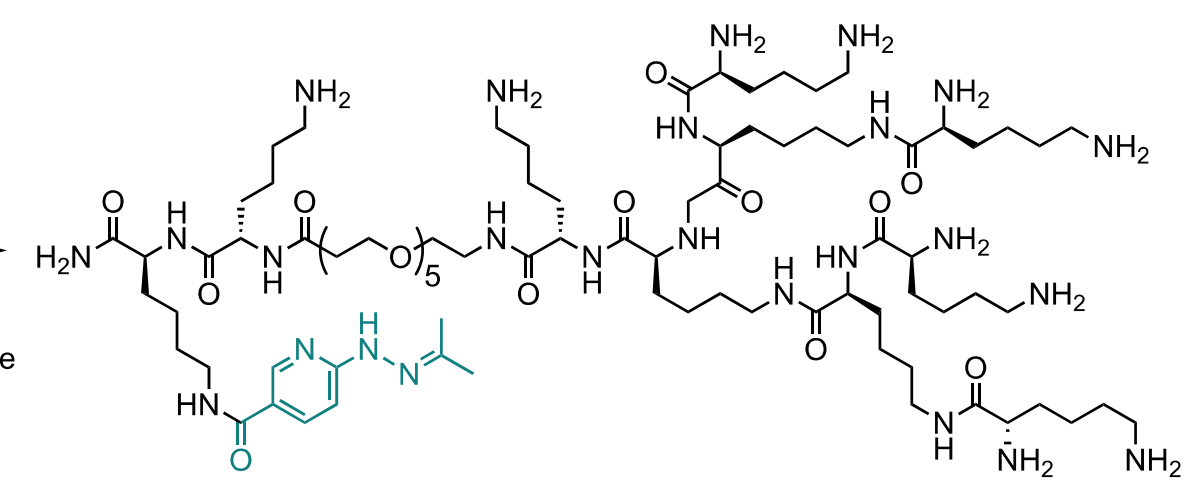

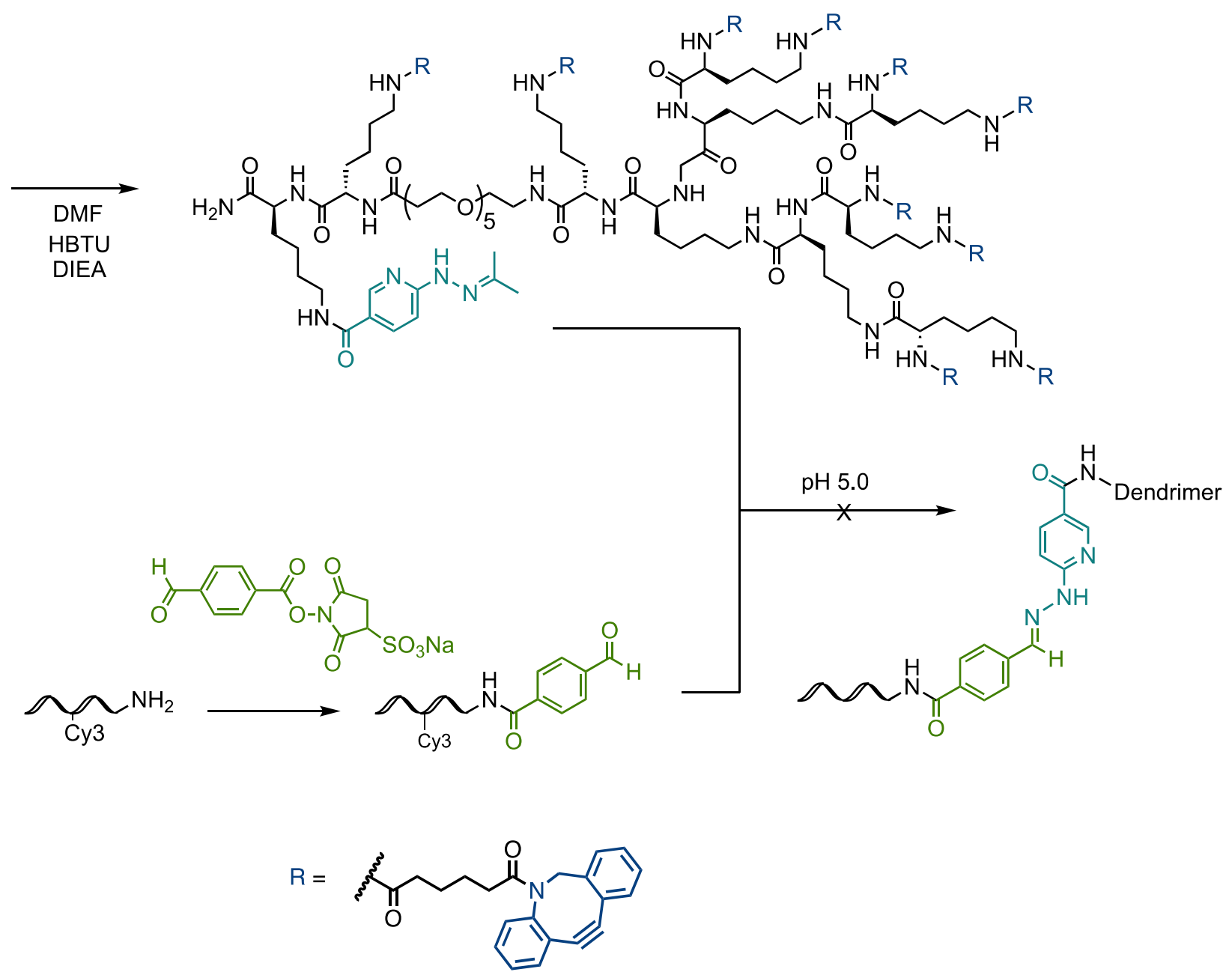

Figure S17. Another synthetic route to conjugate ssDNA with DBCO dendrimer. After labeling the dendrimer scaffold with DBCO in solution, the dendrimer became very hydrophobic and was unable to couple with ssDNA in any common solvents. 


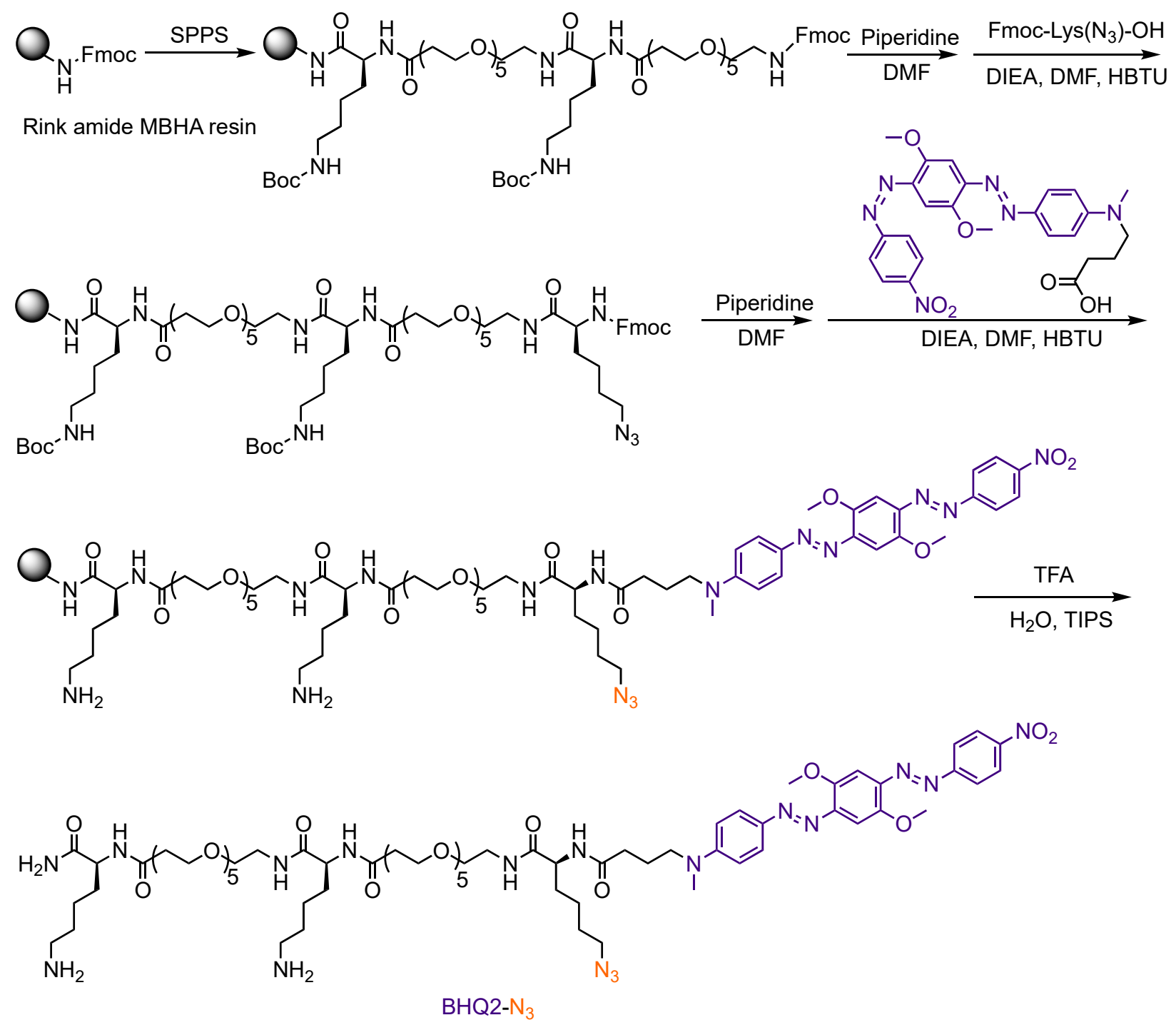

Figure S18. Synthesis of BHQ2-N 3 . Lysine and polyethylene glycol residues were necessary to increase the aqueous solubility. 


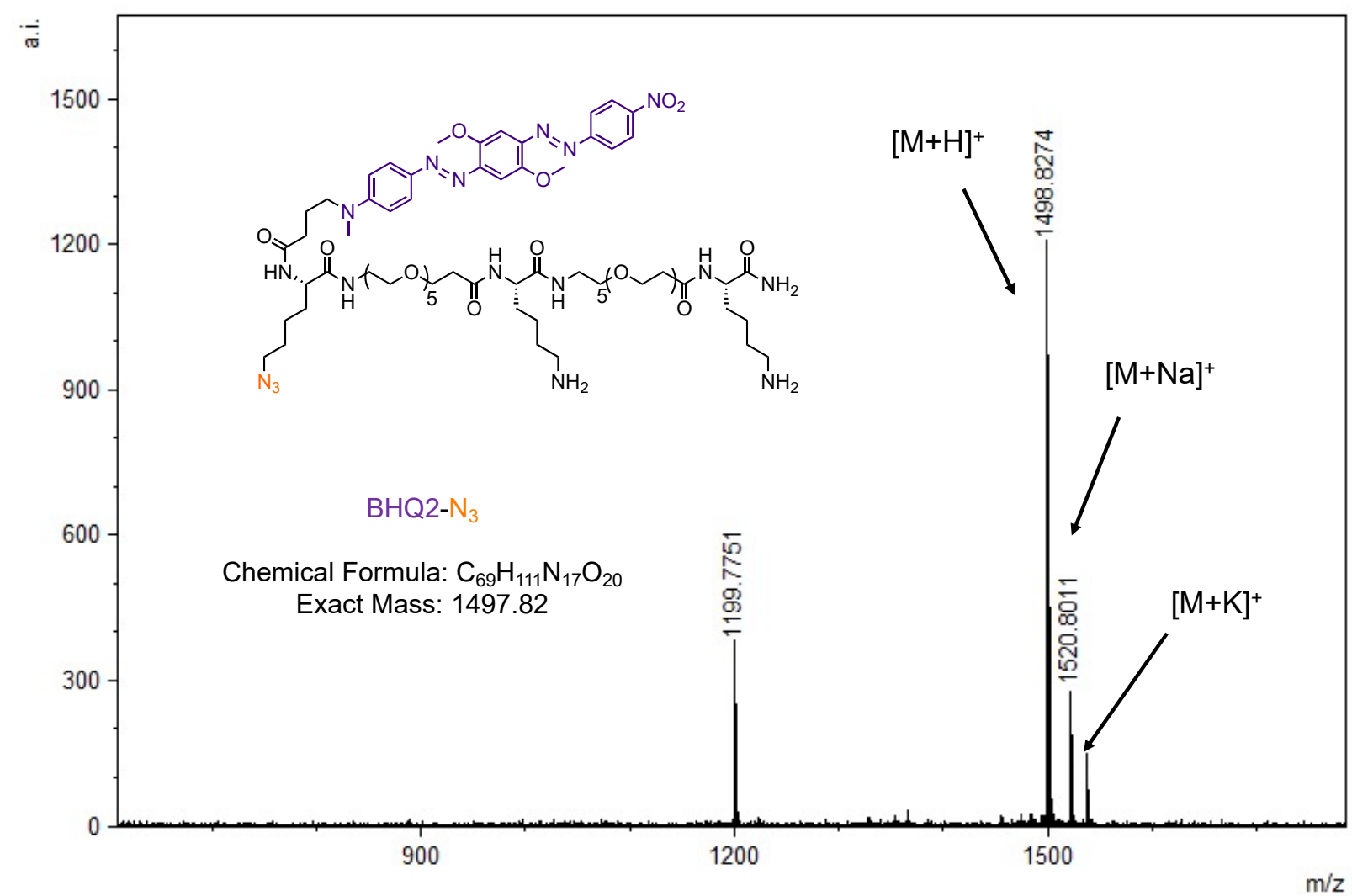

Figure S19. Mass spectrum BHQ2-N 3 (MALDI-TOF). $[\mathrm{M}+\mathrm{H}]^{+}$calculated: 1498.82 , found 1498.83. The 1199 peak corresponds to the photolytic cleavage of the azo bond. ${ }^{1}$

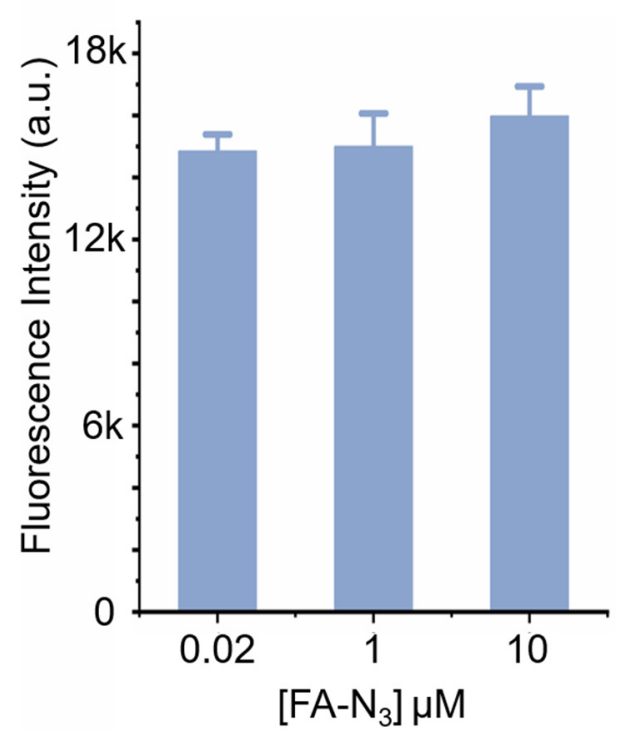

Figure S20. Detecting FA-N 3 with surface-immobilized DBCO-DNA conjugates. No dendrimer structure was involved here, and each ssDNA was conjugated to a single DBCO group. No significant changes were observed with varying concentrations of FA- $\mathrm{N}_{3}$. 


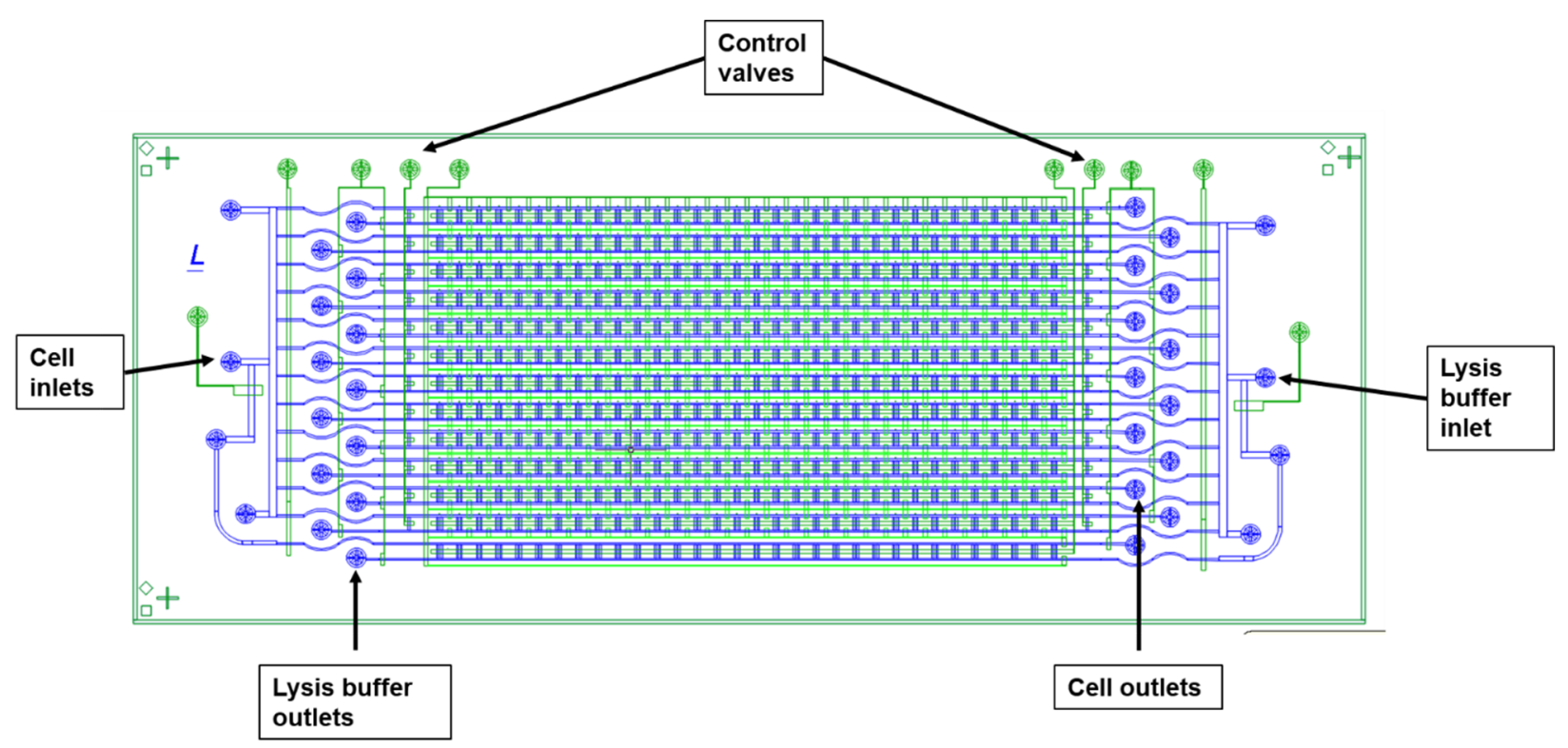

Figure S21. The microfluidics diagram of the SCBC device. The control layer (green) is above the flow layer (blue). The flow path and microchamber access are controlled by changing the control valve pressures. 
a

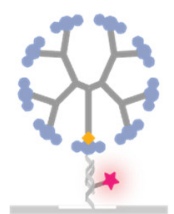

b

FA- $N_{3}$ detection: competitive FRET assay

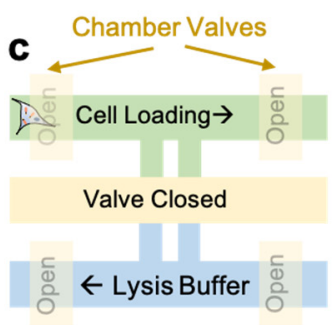

Cell and Lysis

buffer loading

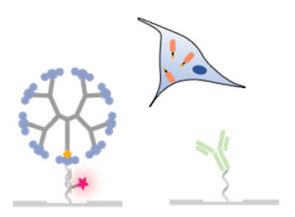

d

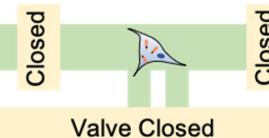

Valve Closed

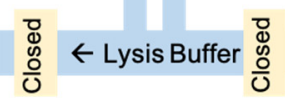

Trap one cell in a chamber

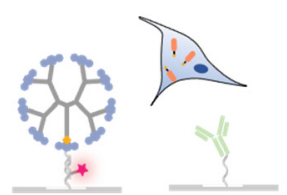

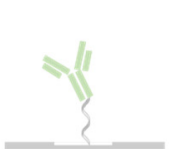
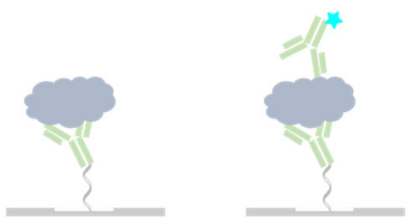

Protein detection: sandwich immunofluorescence

e
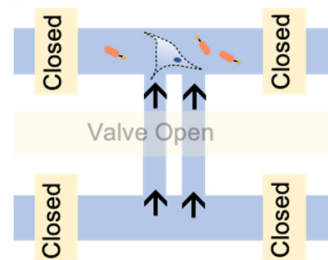

On chip cell lysis

Capture FN- $\mathrm{N}_{3}$ and proteins

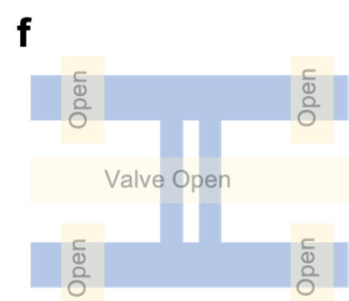

$\mathrm{FN}-\mathrm{N}_{3}$ and proteins detection
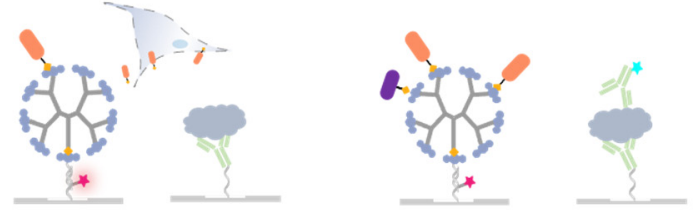

Figure S22. The operation of the SCBC. a) FA-N $\mathrm{N}_{3}$ detection was achieved by a surface-based competitive assay. b) Protein detection was carried out by a sandwich immunofluorescence assay. c-f. Schematic representation of microchamber on the SCBC and the operation protocols. The cells were loaded in the SCBC with FA-N $\mathrm{N}_{3}$ first. Then each cell was isolated and lysed on each chamber. Upon cell lysing, FA-N 3 and other analytes were released from the cell and captured on the surface. Subsequently, the detection cocktail containing BHQ2- $\mathrm{N}_{3}$ and antibodies were added to the chamber, and the fluorescence readout was recorded. The operation of SCBC, except for the fatty acid detection, is well documented in our previous paper. $^{2}$ 


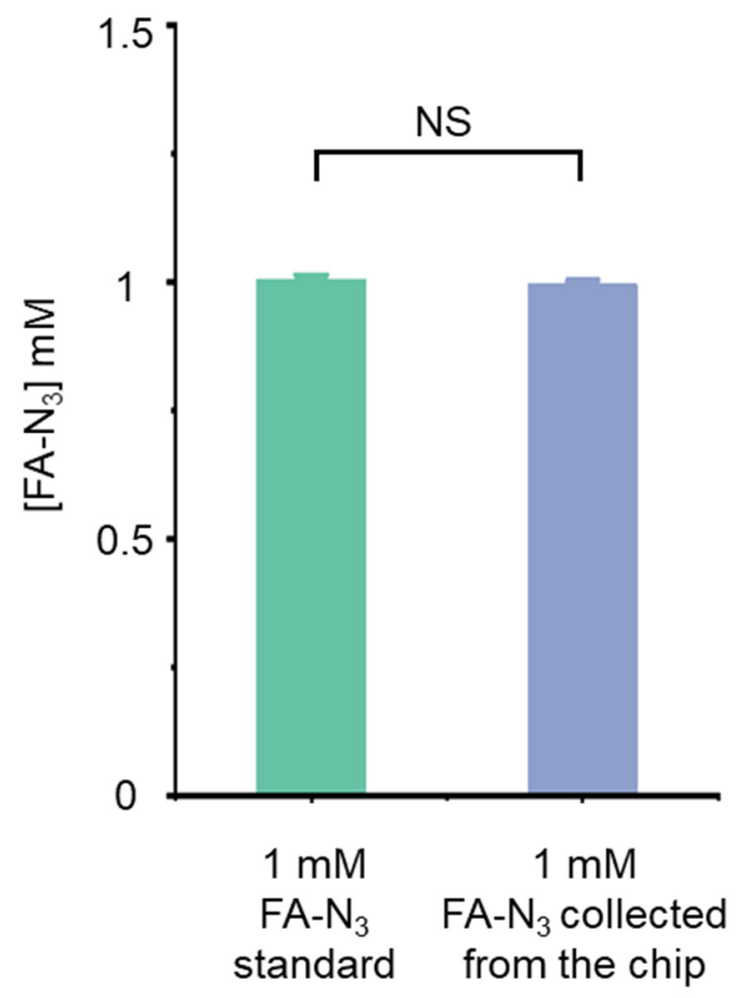

Figure S23. Assessment of the nonspecific binding between azidopentanoic acid (FA-N $\left.\mathrm{N}_{3}\right)$ and the PDMS chip. $1 \mathrm{mM}$ of the $\mathrm{FA}-\mathrm{N}_{3}$ probe was flown through the PDMS device and the resulting solution concentration was compared with the $1 \mathrm{mM} \mathrm{FA-N_{3 }}$ probe solution. Quantitation was performed using NMR $(400 \mathrm{MHz}$, $\mathrm{D}_{2} \mathrm{O}$ ). DMSO was used as an internal standard to calculate the FA- $\mathrm{N}_{3}$ probe concentration. Three datapoints were collected. NS: no statistical difference was observed using t-test. 

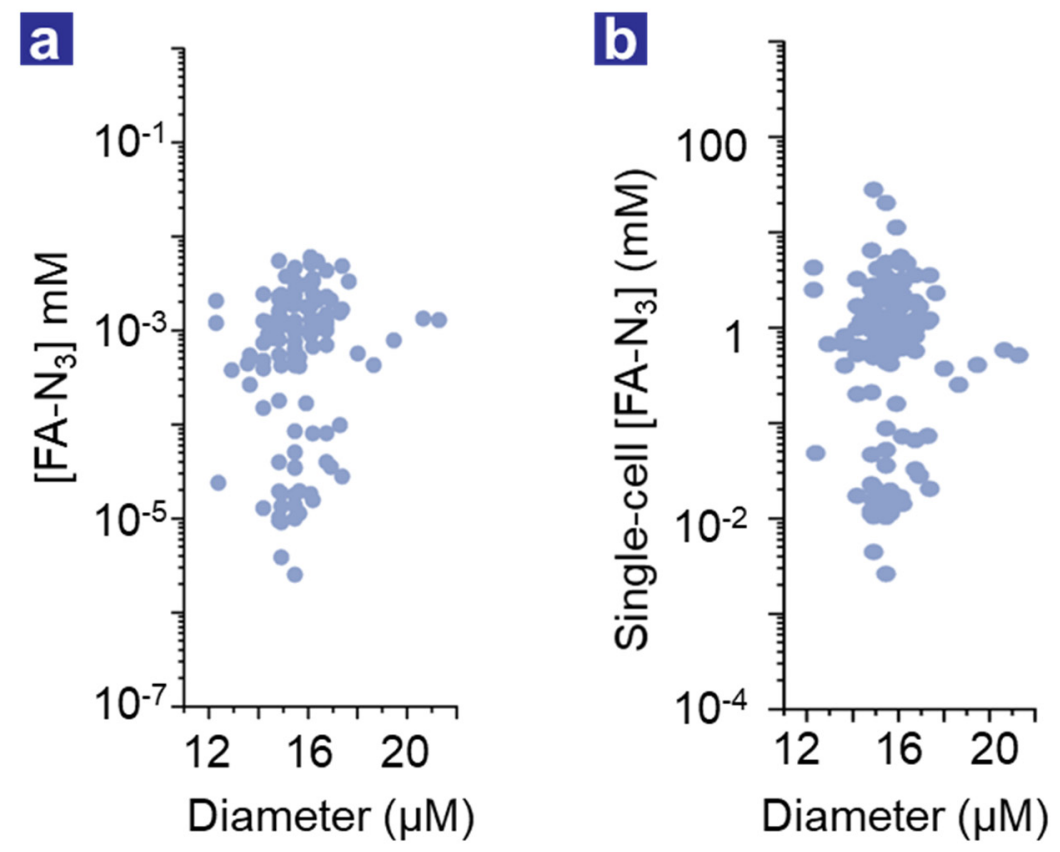

Figure S24. (a) The FA-N 3 concentrations in each single-cell chamber, plotted against the diameter of the cells. No obvious correlation existed. The concentration was calculated from the standard curve in Figure 4b. (b) The intracellular FA-N 3 probe concentration calculated from the amount of the FA- $\mathrm{N}_{3}$ probe, the cell volume, and the chamber volume $(2 \mathrm{~nL})$. The total cell volume was calculated by approximating the cell as a sphere.

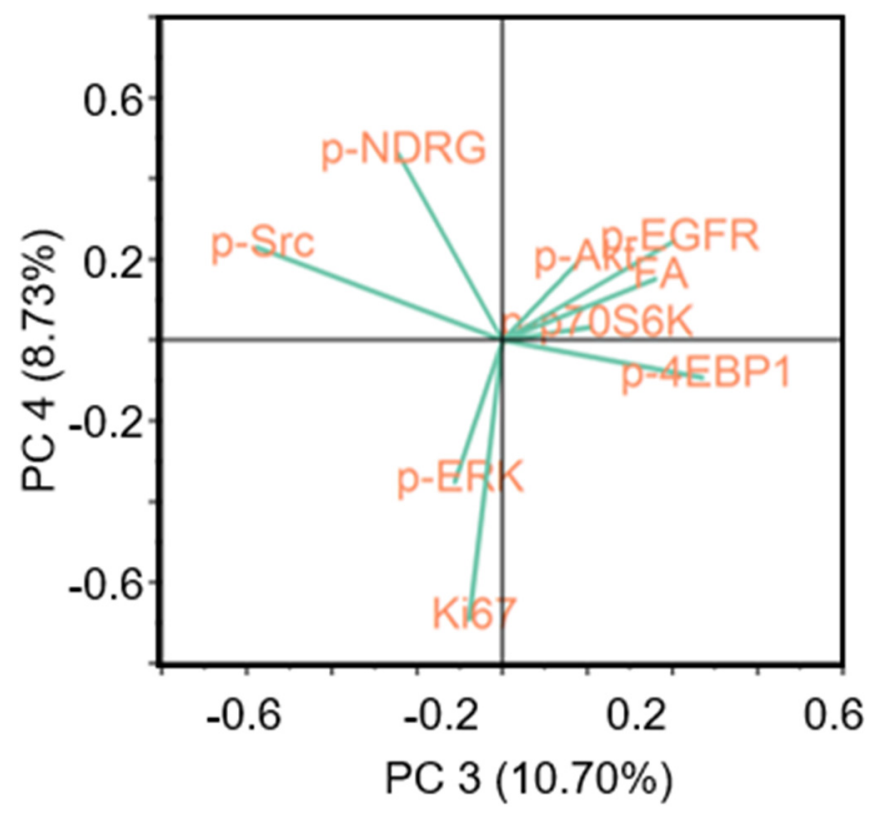

Figure S25. PC 3 and PC 4 loading plot. The relationship between p-Akt and p-70S6K was not consistent with the PC1/PC2 result. 
a

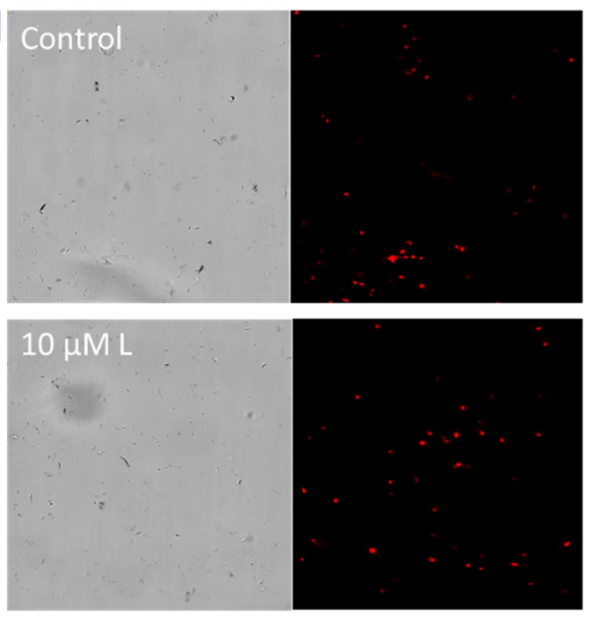

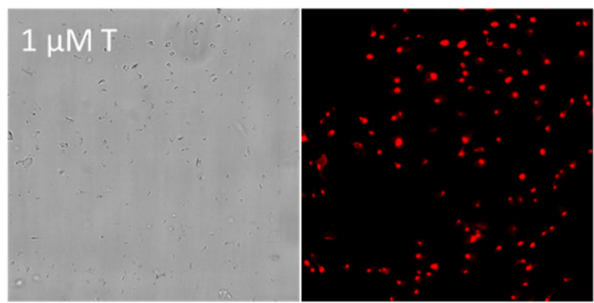

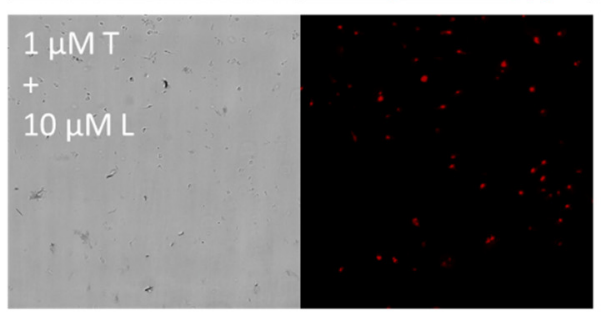

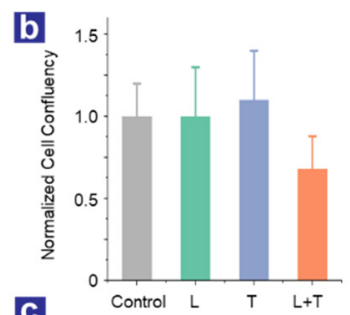

C

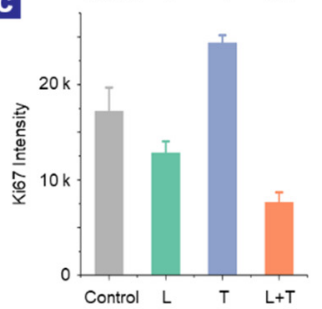

Figure S26. Validation of the cell viability results represented in Figure 6b. (a) Representative Ki67 (cell proliferation marker) immunofluorescence (red) results of U87VIII cells treated with LY2584702 (p70S6K inhibitor, $10 \mu \mathrm{M}$ ) and trimetazidine (fatty acid metabolism inhibitor, $1 \mu \mathrm{M}$ ), and a combination of the two drugs. (b) Normalized cell confluency results generated using an Incucyte $\dagger$ live-cell analysis system. (c) Average Ki67 immunofluorescence intensities quantified using ImageJ.

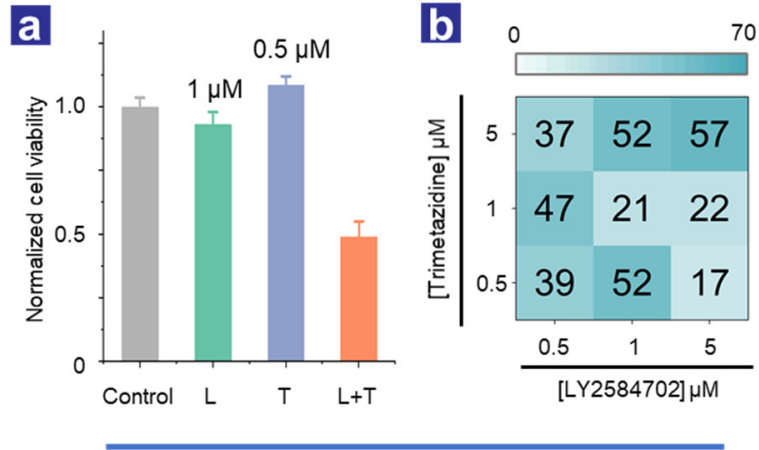

U87 Cells
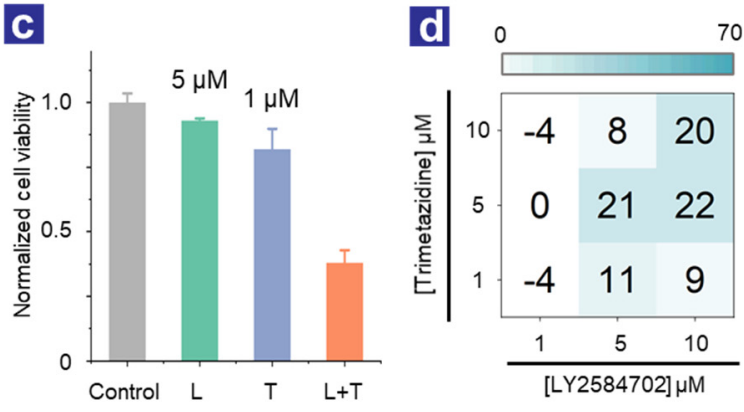

GBM39 Cells

Figure S27. The synergistic effect was also observed in U87 and GBM39 cells. The results from U87 were similar to those obtained from U87VIII. The synergistic effect existed in GBM39 cells, albeit much weaker. (a) U87 cell viabilities as results of LY2584702 $(1 \mu \mathrm{M})$ and trimetazidine $(0.5 \mu \mathrm{M})$ treatments. (b) Synergy scores calculated from the BLISS method across different concentrations of trimetazidine and LY2584702 combinations on U87 cells. (c) GBM39 cell viabilities as results of LY2584702 (5 $\mu \mathrm{M})$ and trimetazidine (1 $\mu \mathrm{M}$ ) treatments. (b) Synergy scores calculated from the BLISS method across different concentrations of trimetazidine and LY2584702 combinations on GBM39 cells. 
Table S1. List of antibodies used in this work

\begin{tabular}{|l|l|}
\hline Capture antibody name & Manufacture \\
\hline Phospho-p70 S6 Kinase (T389) DuoSet & R\&D Systems, DYC896 \\
\hline Human EGFR Antibody, Goat Polyclonal & R\&D Systems, AF231 \\
\hline Human/Mouse/Rat Phospho-ERK1 (T202/Y204) DuoSet & R\&D Systems, DYC1825 \\
\hline Human NDRG1, Goat Polyclonal & R\&D Systems, AF5209 \\
\hline Human Phospho-Src (Y419) DuoSet & R\&D Systems, DYC2685 \\
\hline Human/Mouse 4EBP1 antibody, Goat Polyclonal & R\&D Systems, AF3227 \\
\hline Human/Mouse Phospho-Akt1 (S473) DuoSet & R\&D Systems, DYC2289C \\
\hline Human Ki-67/MKI67, Sheep Polyclonal & R\&D Systems, AF7617 \\
\hline
\end{tabular}

\begin{tabular}{|l|l|}
\hline Detection antibody name & Manufacture \\
\hline Phospho-p70 S6 Kinase (T389) DuoSet & R\&D Systems, DYC896 \\
\hline Phospho-EGF Receptor (Tyr1173) Antibody, Rabbit Monoclonal & Cell Signaling, 4407S \\
\hline Human/Mouse/Rat Phospho-ERK1 (T202/Y204) DuoSet & R\&D Systems, DYC1825 \\
\hline Phospho-NDRG1 (Thr346) Antibody, Rabbit Monoclonal & Cell Signaling, 7497S \\
\hline Human Phospho-Src (Y419) DuoSet & R\&D Systems, DYC2685 \\
\hline Phospho-4E-BP1 (Thr37/46) Antibody, Rabbit Monoclonal & Cell Signaling, 5132S \\
\hline Human/Mouse Phospho-Akt1 (S473) DuoSet & R\&D Systems, DYC2289C \\
\hline Ki-67 Antibody, Rabbit Monoclonal & Cell Signaling, 12075S \\
\hline
\end{tabular}




\section{Materials:}

Rink amide MBHA resin (loading capacity $0.68 \mathrm{mmol} / \mathrm{g}$ ) was purchased from Aapptec (Louisville, KY). All of the Fmoc-protected amino acids were purchased from Anaspec (Fremont, CA) except Fmoc-ILys(Fmoc)-OH and Fmoc-Lys(N3)-OH (Az4), which were purchased from Chem-Impex (Wood Dale, IL). BHQ2 carboxyl acid and Fmoc-PEG5-OH were purchased from Biosearch Technologies (Petaluma, CA) and BroadPharm (San Diego, CA), respectively. S-HyNic and S-4FB were purchased from TriLink BioTechnologies (San Diego, CA). The coupling reagent 2-(1H-benzotriazol-1-yl)-1,1,3,3tetramethyluronium hexafluorophosphate (HBTU, 99.6\%) was obtained from Chem-Impex (Wood Dale, IL). Diisopropylethylamine (DIEA, 99.5\%) was purchased from ACROS (Germany). Triisopropylsilane (TIPS) was obtained from TCl (Portland, OR). Piperidine was purchased from Alfa Aesar (Ward Hill, MA). a-cyano4-hydroxycinnamic acid (CHCA) was obtained from Sigma-Aldrich (St. Louis, MO). Tris base, sodium phosphate dibasic anhydrous $\left(\mathrm{Na}_{2} \mathrm{HPO}_{4}, 99.6 \%\right)$, sodium phosphate monobasic monohydrate $\left(\mathrm{NaH}_{2} \mathrm{PO}_{4}\right.$, $99.4 \%$ ), sodium chloride ( $\mathrm{NaCl}$ ), ascorbic acid, Tween 20 , sodium dodecyl sulfate (SDS), bovine serum albumin (BSA), acetonitrile $\left(\mathrm{CH}_{3} \mathrm{CN}\right)$, diethyl ether $\left(\mathrm{Et}_{2} \mathrm{O}\right)$, ethyl acetate $(\mathrm{EA}), N, N^{\prime}$-dimethylformamide (DMF), and dichloromethane (DCM) were purchased from Thermo Fisher Scientific (Waltham, MA). DNACy3-NH 2 (5'- /5AmMC6/AAA AAA AAA AAA /iCy3/TGC TCG GGA AGG CTA CTC -3') was ordered from Integrated DNA Technologies, Inc. (Coralville, IA). DBCO-C6-Sulfo-NHS was purchased from Click Chemistry Tools (Scottsdale, AZ).

\section{Experiment:}

\section{Solid-phase peptide synthesis}

Peptides were synthesized on Rink Amide MBHA resin via the standard Fmoc solid-phase peptide synthesis (SPPS) chemistry. For Fmoc deprotection, the resin was agitated with piperidine $(20 \% \mathrm{v} / \mathrm{v}$ in DMF, $3 \times 5 \mathrm{~min}$ ) and washed with DMF 5 times. To couple amino acids to the resin, a DMF solution of Fmoc$\mathrm{AA}$ (protection group)-OH (5 eq.), HBTU (4.75 eq), and DIEA (15 eq.) was mixed for 3 minutes, and then the mixture was added to the resin and agitated at room temperature for 1 hour. For peptide side-chain

global deprotection and cleavage, the resin was washed with DCM and dried with compressed airflow. The beads were then cleaved in a TFA cleavage solution (TFA: TIPS: ddH2O; 95:2.5:2.5) for 2 hour. All peptides were purified on the RP-HPLC (DIONEX Ultimate 3000; Thermo Scientific, Germany) using a C18 reversedphase preparative column (Kinetex. $5 \mu \mathrm{m}$ EVO, $250 \AA \sim 21.2 \mathrm{~mm}$ ) or a C18 reversed-phase semipreparative column (Kinetex. $5 \mu \mathrm{m}$ EVO, $250 \AA \sim 10 \mathrm{~mm}$ ). The product was validated using MALDI-TOF MS (AB SCIEX TOF/TOF 5800, Framingham, MA) and lyophilized for long-term storage at $-20^{\circ} \mathrm{C}$. 


\section{Synthesis of azide-attached poly-lysine dendrimers}

The azide-attached poly-lysine dendrimer scaffolds were synthesized on rink amide MBHA resin following standard SPPS protocols. The synthetic scheme is shown in Figure 2a. Fmoc-I-Lys(N3)-OH and FmocPEG5-OH were attached to the resin first, followed by 3 or 4 rounds of Fmoc-I-Lys(Fmoc)-OH coupling. Before the cleavage, the Fmoc protecting groups were removed by piperidine. After the cleavage and HPLC purification, the dendrimer scaffolds were characterized by MALDI-TOF MS and lyophilized for storage. G-3 poly-lysine dendrimer: ${ }^{1} \mathrm{H}$ NMR $\left(400 \mathrm{MHz}, \mathrm{D}_{2} \mathrm{O}\right.$, as a TFA salt) $\delta 4.19(\mathrm{t}, J=7.1 \mathrm{~Hz}, 1 \mathrm{H}), 4.16-4.04$ $(\mathrm{m}, 3 \mathrm{H}), 3.90(\mathrm{t}, J=6.6 \mathrm{~Hz}, 2 \mathrm{H}), 3.80(\mathrm{t}, J=6.6 \mathrm{~Hz}, 2 \mathrm{H}), 3.66(\mathrm{t}, J=5.9 \mathrm{~Hz}, 2 \mathrm{H}), 3.63-3.51(\mathrm{~m}, 16 \mathrm{H}), 3.48$ $(\mathrm{t}, J=5.3 \mathrm{~Hz}, 2 \mathrm{H}), 3.32(\mathrm{dt}, J=10.6,5.3 \mathrm{~Hz}, 1 \mathrm{H}), 3.27-3.17(\mathrm{~m}, 3 \mathrm{H}), 3.16-2.96(\mathrm{~m}, 8 \mathrm{H}), 2.87(\mathrm{dd}, J=$ $14.9,7.3 \mathrm{~Hz}, 8 \mathrm{H}), 2.46(\mathrm{t}, J=5.9 \mathrm{~Hz}, 2 \mathrm{H}), 1.89-1.70(\mathrm{~m}, 9 \mathrm{H}), 1.70-1.53(\mathrm{~m}, 16 \mathrm{H}), 1.52-1.37(\mathrm{~m}, 9 \mathrm{H})$, $1.36-1.17(\mathrm{~m}, 17 \mathrm{H}), 1.14(\mathrm{t}, J=7.3 \mathrm{~Hz}, 3 \mathrm{H}) \cdot{ }^{13} \mathrm{C}$ NMR $\left(100 \mathrm{MHz}, \mathrm{D}_{2} \mathrm{O}\right.$, as a TFA salt, the signal of TFA was not included) $\delta 177.01,174.36,173.68,173.29,173.13,169.53,169.48,169.26,69.56,69.37,68.71$, $66.71,54.25,54.11,53.76,53.52$, 53.10, 52.68, 50.82, 46.65, 39.29, 39.16, 38.94, 38.87, 35.75, 30.70, 30.43, 30.36, 28.03, 27.66, 27.94, 27.89, 27.47,26.34, 22.52, 22.42, 21.32, 21.16, 8.20.

G-4 poly-lysine dendrimer: ${ }^{1} \mathrm{H}$ NMR $\left(400 \mathrm{MHz}, \mathrm{D}_{2} \mathrm{O}\right.$, as a TFA salt) $\delta 4.26-3.99(\mathrm{~m}, 8 \mathrm{H}), 3.90(\mathrm{t}, \mathrm{J}=6.6$ $\mathrm{Hz}, 4 \mathrm{H}$ ), 3.80 (t, J=6.6 Hz, 4H), $3.66(\mathrm{t}, J=5.9 \mathrm{~Hz}, 2 \mathrm{H}), 3.61-3.49(\mathrm{~m}, 16 \mathrm{H}), 3.48(\mathrm{t}, J=5.3 \mathrm{~Hz}, 2 \mathrm{H}), 3.30$ (dd, $J=12.4,7.1 \mathrm{~Hz}, 1 \mathrm{H}), 3.26-3.16(\mathrm{~m}, 3 \mathrm{H}), 3.16-2.93(\mathrm{~m}, 16 \mathrm{H}), 2.87(\mathrm{dd}, J=15.0,7.3 \mathrm{~Hz}, 16 \mathrm{H}), 2.46$ $(\mathrm{t}, J=5.9 \mathrm{~Hz}, 2 \mathrm{H}), 2.01-1.66(\mathrm{~m}, 18 \mathrm{H}), 1.69-1.45(\mathrm{~m}, 32 \mathrm{H}), 1.49-1.05(\mathrm{~m}, 50 \mathrm{H}) .{ }^{13} \mathrm{C} \mathrm{NMR}(100 \mathrm{MHz}$, $\mathrm{D}_{2} \mathrm{O}$, as a TFA salt, the signal of TFA was not included) $\delta 176.99,174.33,173.71,173.38,173.13,169.52$, $169.28,169.23$, 69.57, 69.41, 68.73, 66.73, 54.25, 54.09, 53.75, 53.52, 53.10, 52.71, 50.82, 46.64, 39.30, $38.85,35.76,30.82,30.67,30.41,30.37,28.12,28.04,27.90,27.47,26.34,26.29,22.56,22.43,21.33$, $21.19,8.20$.

\section{Conjugation of DBCO to ssDNA-Cy3- $\mathrm{NH}_{2}$}

$50 \mu \mathrm{L}$ of ssDNA-Cy3-DBCO solution $(250 \mu \mathrm{M}$, in $1 \mathrm{X}$ PBS, pH 7.4) was mixed with $10 \mu \mathrm{L}$ of DBCO-SulfoNHS solution (12.5 $\mu \mathrm{L}, 10 \mathrm{mM}$ in 1X PBS) for 2 hours. After incubation, the mixture was purified by Zeba spin columns to remove unreacted small molecules. The concentration of ssDNA-Cy3-DBCO was determined by UV-Vis absorbance at $550 \mathrm{~nm}$. The quality of the reaction was confirmed by FPLC and HPLC.

\section{Conjugation of the poly-lysine dendrimers (1 and 2) to ssDNA}

$50 \mu \mathrm{L}$ of ssDNA-Cy3-DBCO solution ( $200 \mu \mathrm{M}$, in 3X PBS, pH 7.4) was mixed with $10 \mu \mathrm{L}$ of poly-lysine dendrimer scaffold (10 mM, in $3 X$ PBS, $\mathrm{pH} 7.4)$ at $37^{\circ} \mathrm{C}$ for 6 hours. After incubation, the mixture was purified by FPLC to obtain ssDNA-dendrimer scaffold conjugates. The concentrations of the conjugates were determined by their UV-Vis absorbance at $550 \mathrm{~nm}$. 


\section{Labeling the ssDNA-dendrimer conjugates (3 and 4) with DBCO}

$50 \mu \mathrm{L}$ of ssDNA-dendrimer scaffold conjugates (100 $\mu \mathrm{M}$ in 3X PBS) was mixed with $20 \mu \mathrm{L}$ of DBCO-SulfoNHS ester solution (10 $\mathrm{mM}$ for $3^{\text {rd }}$ generation, $20 \mathrm{mM}$ for $4^{\text {th }}$ generation, in $3 \mathrm{X} \mathrm{PBS}, \mathrm{pH}$ 7.4). The mixture was incubated at room temperature overnight. The final products were purified by FPLC and stored at $4{ }^{\circ} \mathrm{C}$. The concentrations of the DBCO dendrimers and the number of DBCO on each dendrimer were determined by UV-Vis absorbance at $550 \mathrm{~nm}$ and $310 \mathrm{~nm}$, respectfully.

\section{Immobilization of the dendrimer on a glass surface.}

A 16-well (50 $\mu \mathrm{L}$ each) PDMS slab was placed onto a microscope glass slide patterned with ssDNA strands that are complementary to the oligonucleotide sequence on DBCO dendrimers. Each well was blocked with $50 \mu \mathrm{L}$ of $1 \% \mathrm{BSA}$ in $1 \times \mathrm{PBST}$ at room temperature for 1 hour. Afterward, the blocking solution was removed, and $45 \mu \mathrm{L}$ of dendrimer (100 nM in 1\% BSA, 1X PBST) was added to each well. After 1 hour of incubation at room temperature, each well was washed with 1X PBST three times. At this point, the dendrimer was immobilized on the device and ready to use.

\section{Generation of the FA-N 3 response curve via a surface-based competition assay.}

The $3^{\text {rd }}$ or $4^{\text {th }}$ generation dendrimer was immobilized on the glass slide surface (described above). To generate a working curve of FA- $\mathrm{N}_{3}, 45 \mu \mathrm{L}$ of FA-N $\mathrm{N}_{3}$ (various concentrations in 1X PBST) was added to each well. The slide was incubated at $37^{\circ} \mathrm{C}$ for 2 hours, allowing FA-N $\mathrm{N}_{3}$ to react with the DBCO groups on the dendrimer. The FA-N $\mathrm{N}_{3}$ solution was then removed, and each well was washed with 1X PBST three times. $45 \mu \mathrm{L}$ of BHQ2- $\mathrm{N}_{3}$ solution ( $25 \mu \mathrm{M}$ in $1 \mathrm{X}$ PBST) was added to each well, and the slide/PDMS device was incubated at $37^{\circ} \mathrm{C}$ for 1 hour, allowing BHQ2-N $\mathrm{N}_{3}$ to react with unoccupied DBCO sites. After removing the BHQ2-N $\mathrm{N}_{3}$ solution, and the device was washed with $1 \mathrm{X}$ PBST three times. The PDMS slab was then removed, and the slide was washed with $1 \mathrm{X}$ PBS, 50\% 1X PBS/water, and water. The slide was then airdried, and the fluorescence intensities were obtained using a Genepix microarray scanner. Experiments were run in quadruplets to get the error bar.

\section{BHQ2-N $\mathrm{N}_{3}$ optimization on the surface platform.}

The $3^{\text {rd }}$ generation dendrimer was first immobilized on the glass slide as described above. To scan for an optimal BHQ2- $\mathrm{N}_{3}$ concentration, $45 \mu \mathrm{L}$ of FA-N $\mathrm{N}_{3}$ (100 $\mu \mathrm{M}$ in 1X PBST) was added to each well. The device was left at $37^{\circ} \mathrm{C}$ for 2 hours. The FA-N 3 solution was taken out, and each well was washed with $1 \times$ PBST three times. $45 \mu \mathrm{L}$ of BHQ2-N $\mathrm{N}_{3}$ (various concentrations in 1X PBST) was then added to each well, and the device was kept at $37^{\circ} \mathrm{C}$ for 1 hour, allowing BHQ2- $\mathrm{N}_{3}$ to react with unoccupied DBCO sites. Afterward, the solution was removed, and the device was washed with 1X PBST three times. After the 16-well PDMS slab was removed from the device, the glass chip was washed with $1 \mathrm{XPBS}, 50 \% 1 \mathrm{xPBS} /$ water, and water. The chip was airdried, and the fluorescence intensities were obtained using a Genepix microarray scanner. Experiments were run in quadruplets to obtain the error bar. 


\section{Cell culture}

U87vlll cell line was provided as a gift by Prof. Paul Mischel (UCSD, San Diego, U.S.A.). Cells were cultured in Dulbecco's Modified Eagle Media with high glucose, pyruvate (DMEM, Thermo), heat-inactivated fetal bovine serum (FBS), $100 \mathrm{U} / \mathrm{mL}$ of penicillin-streptomycin, and 250ng/mL Amphotericin $\mathrm{B}$ (Thermo) in a humidified $5 \% \mathrm{CO}_{2}(\mathrm{v} / \mathrm{v})$ incubator at $37^{\circ} \mathrm{C}$.

\section{FA-N 3 tolerance experiment}

A 96-well plate was seeded with U87 cells (10k/well), and the cells were allowed to grow overnight. Then the FA- $\mathrm{N}_{3}$ solution was added ( $100 \mu \mathrm{L}$ per well, various concentrations) to the cells and incubated for 24 hours. After the incubation, the cell media was removed, and a resazurin solution $(10 \mu \mathrm{g} / \mathrm{mL}$, in cell media) was added to the plate and incubated for 2 hours. The fluorescence was read by a plate reader (Biotek, $540 \mathrm{~nm}$ excitation/ $590 \mathrm{~nm}$ emission).

\section{FA-N 3 uptake experiment at the bulk level}

The U87 cells were collected via centrifugation at $500 \mathrm{~g}$ for $5 \mathrm{~min}$. The media was removed, and the cells were resuspended in FBS-free DMEM, resulting in a $4 \mathrm{M}$ cells $/ \mathrm{mL}$ suspension. $250 \mu \mathrm{L}$ of the cell suspension was dispensed into Eppendorf tubes, and mixed with $250 \mu \mathrm{L}$ of the $\mathrm{FA}-\mathrm{N}_{3}$ solution (various concentrations, in FBS free DMEM). After $30 \mathrm{~min}$ incubation in the cell incubator, the cells were centrifuged at $500 \mathrm{~g}$ for 5 min and the resulting pellet was washed 3 times to remove any excess FA-N $N_{3}$. Then, $100 \mu \mathrm{L}$ cell lysis buffer was added to each tube, and kept on ice for $15 \mathrm{~min}$. The tubes were then sonicated and vortexed for $5 \mathrm{~min}$. Finally, the tubes were centrifuged at maximum speed for 10 min. The supernatant was collected and subjected to surface-based $\mathrm{FA}-\mathrm{N}_{3}$ detection.

\section{Single-cell suspension preparation}

To harvest the cells, the culture media was gently aspirated without disturbing the cells. The cells were then washed with PBS and further treated with $0.05 \%$ trypsin for $5 \mathrm{~min}$ at $37{ }^{\circ} \mathrm{C}$, followed by the addition of an equal volume of culture media to terminate the trypsinization process. The collected cells were then pelleted via centrifugation at $500 \mathrm{~g}$ for $5 \mathrm{~min}$. After discarding the supernatant, the cells were then disassociated as single cells and ready for tests.

For SCBC measurements, the as-prepared single cells were resuspended in warm FBS-free media supplemented with $10 \mathrm{mM} \mathrm{FA-N}{ }_{3}$ at $2 \mathrm{M}$ cells $/ \mathrm{mL}$. After being incubated at $37^{\circ} \mathrm{C}$ for 30 min and washed with FBS-free media 3 times, the collected cell pellet was resuspended in serum-free, biotin-free media. The concentration of the as-prepared single-cell suspension was $2 \mathrm{M}$ cells $/ \mathrm{mL}$. 


\section{Single-cell metabolic/proteomic measurements}

The single-cell barcode chips (SCBC) were fabricated according to well-established procedures. ${ }^{2}$ DNAencoded antibody library (DEAL) was grafted onto the surface through DNA hybridization to enable capture antibody arrays. The FA surface probe was also incorporated onto the surface barcode through the same procedure. The devices were operated following previously established protocols. A concise description is shown in Figure S22.

\section{Image acquisition and data extraction}

At the end of the mini well assay and the SCBC assay, the glass slides were detached from the PDMS device, and the surface fluorescence was analyzed using a microarray scanner (Genepix 4400A, $532 \mathrm{~nm}$ excitation / standard green filter; $635 \mathrm{~nm}$ excitation / standard red filter). Examples of the raw images were shown in Figure 3a and Figure 4a. To extract the quantitative data, the fluorescence intensity at each pixel was exported using the Genepix software. The median fluorescence intensity value of the pixels on each barcode strip was used as a datapoint for that specific analyte.

\section{Statistical analysis}

The single-cell data was obtained as a matrix, where each row represented a single cell, and each column was the intensity of one analyte. Statistical analysis of this dataset was performed in OriginPro $2019 \mathrm{~b} \circledast$ software. The dataset was first standardized on each column to obtain the $Z$ score of each value. The Euclidean distance values between data points were calculated and tabulated as a matrix. This distance matrix was then used as the input for agglomerative hierarchical clustering using Ward's method. To perform principal component analysis, the standardized single-cell dataset was used as input. The correlation coefficient was directly calculated from the data set by Spearman's rank method. Analyteanalyte correlation networks were generated by running the calculation through all the analyte pairs in the panel, and only those significant correlations (with Bonferroni correction) were shown in the networks. The network was presented as a Circos plot. ${ }^{3}$

\section{Drug synergy measurements}

To ensure optimal cell attachment, $100 \mu \mathrm{L}$ of $10 \mu \mathrm{g} / \mathrm{mL}$ laminin was added into each well of a 96-well plate, and the plate was incubated at $4^{\circ} \mathrm{C}$ overnight. Afterward, the plate was washed with PBS three times. 100 $\mu \mathrm{L}$ of $\mathrm{U} 87 \mathrm{vlll}$ cell suspension at $50 \mathrm{k} / \mathrm{mL}$ was then added into each well, and the plate was incubated at $37^{\circ} \mathrm{C}$ overnight. On the second day, the media was changed to $200 \mu \mathrm{L}$ of fresh media containing various concentrations of trimetazidine, and LY2584702. The cells were cultured for another $48 \mathrm{hrs}$. Subsequently, $20 \mu \mathrm{L}$ of $0.2 \mathrm{mg} / \mathrm{mL}$ resazurin PBS solution was added into each well, followed by incubation at $37^{\circ} \mathrm{C}$ for 3 hrs. The resulting fluorescent signals were recorded by a plate reader ( $560 \mathrm{~nm}$ excitation / $590 \mathrm{~nm}$ emission). The synergy scores of the two drugs were calculated by using the following equation:

$S_{A, B}=I_{A, B}-\left(I_{A}+I_{B}-I_{A} \times I_{B}\right)$ 
where $S_{A, B}$ is the synergy effect between drugs $A$ and $B, I_{A, B}$ is the cell-killing efficiency by using the combination of drug $A$ and $B$, while $I_{A}$ and $I_{B}$ are the cell-killing efficiencies from independent doses of drug A or $B$, respectively.

\section{References}

1. Wyplosz, N. Laser desorption mass spectrometric studies of artists' organic pigments. University of Amsterdam, 2003.

2. Xue, M.; Wei, W.; Su, Y.; Kim, J.; Shin, Y. S.; Mai, W. X.; Nathanson, D. A.; Heath, J. R., Chemical methods for the simultaneous quantitation of metabolites and proteins from single cells. $J$ Am Chem Soc 2015, 137 (12), 4066-9.

3. Krzywinski, M.; Schein, J.; Birol, I.; Connors, J.; Gascoyne, R.; Horsman, D.; Jones, S. J.; Marra, M. A., Circos: an information aesthetic for comparative genomics. Genome Res 2009, 19 (9), 1639-1645. 